\title{
Gender Abuse in Intimate Relationships: From Structural Coupling Theory to Emergence of Couple System
}

\author{
Rosalia Condorelli \\ Department of Political and Social Sciences, University of Catania, Catania, Italy \\ Email:rcondor@unict.it
}

How to cite this paper: Condorelli, R. (2017). Gender Abuse in Intimate Relationships: From Structural Coupling Theory to Emergence of Couple System. Sociology Mind, 7, 197-256.

https://doi.org/10.4236/sm.2017.74013

Received: August 10, 2017

Accepted: October 15, 2017

Published: October 18, 2017

Copyright $\odot 2017$ by author and Scientific Research Publishing Inc. This work is licensed under the Creative Commons Attribution International License (CC BY 4.0).

http://creativecommons.org/licenses/by/4.0/

\section{(c) (i) Open Access}

\begin{abstract}
Is love predictable in its choices? Linear Determinism, Randomness or Complexity? By applying theoretical coordinates of current sociological interpretations of intimacy and conceptual categories of New General System Theory, the paper reflects on one-factor and linear determinism implicitly underlying mate selection processes in Structural Coupling Theory and its implications for Intimate Partner Violence (IPV). Assuming personality structure as the predictor of partner choice as well as victimization risk, SCT circumscribes victimization risk just to one category of women (insecure/avoidant women coupling with ambivalent partners). We propose that adaptive complex system and non-banai machine concepts are more effective to understand the mate selection process than linear deterministic approach, which appears too mechanistic for a process that exhibits an inextricable dimension of uncertainty and unpredictability. Research results on a sample of 100 victims of IPV do not corroborate the linear one-factor determinism underlying Structural Coupling Theory neither its implications. Rather they go in the direction of Complexity.
\end{abstract}

\section{Keywords}

Gender Abuse, Partner Choice, Love and Identity in Post-Modern Societies, The Volatility of Love, Emergence of Couple System, Complexity and Nonlinearity, Adaptive Complex Systems

\section{Introduction: Just a Matter of Personality? A theoretical Re-Framing from the Perspective of Social Systems' Non-Linearity}

How we understand a relationship in which the same victims have opened the doors of their intimate life to the one who is their abusive partner? Why women 
choice a partner able to victimize them in such a tragic manner? Maybe the choice is too hasty, little weighted? Maybe it's just a matter of personality...? If what is here put in the form of a question is often a conviction in the plan of common places, this interpretative hypothesis finds place in the field of Behavioural Psychology. Here, Structural Coupling Theory explains victimization risk by postulating a discriminating factor between normal and dysfunctional couples strongly depending on partners' personality structure, which is the predictor of partner choice as well as victimization risk in Intimate Partner Violence (IPV) against women ${ }^{1}$. The analytical path I intend to propose with this essay is a reflection on the foundations of Structural Coupling Theory and its implications for $\mathrm{IPV}^{2}$, starting from a reconsideration of Theory core, which is no longer sustainable in the light of New General System Theory. The point at issue is not the incidence of personality-psychological factors in the partner's choice but the linear determinism implicitly underlying conception of the couple system and mate selection process, which, then, pushes for admitting the existence of a victim's type (women with insecure/avoidant personality coupling with ambivalent partner) and, consequently, to the extent that the field of the victimization is circumscribed just to one category of women, a risk of victimization which strongly depends on personality structure.

This implicit deterministic foundation derive from Bowlby's Attachment Theory (duly systemized in his three volumes of Attachment and Loss-Bowlby (1969; 1973a; 1980) and already anticipated by his work in 1958, 1960a and 1960b (Bowlby, 1958; 1960a; 1960b), whose resonance was so vast to connect the Attachment Theory to psychoanalysis, to the ideas of Freud, Klein, and Winnicott who were not certainly unknown to Bowlby), of which Structural Coupling Theory represents a subsequent development. Bowlby (1973b: 24) believed that family relationships pattern a person experienced in childhood had a crucial importance for the development of his or her personality and for all present and future relationships, including those intimate. Consequently, couple system was nothing more than the result of the interaction between two relational experiences including the personal attachment style (secure, avoidant and ambivalent attachment styles) and the model of self-perception and of others, produced and intro-ejected through parental relationship. These factors, Bowlby (1973b: 24) said, greatly influence the nature of the expectations that a person has, its cognitive map, its way of seeing and representing world. The nature of person's expectations play a larg part in determining the kinds of person with whom she or

${ }^{1}$ Alì \& Naylor (2013: 374) emphasize that IPV term expresses the "fact that violence can be perpetuated by both men and women with no limitation on their marital status or the heterosexual or homosexual nature of their relationship" (Alì \& Naylor, 2013: 374). Nevertheless, IPV is often thought to be violence against women (VAW) perpetuated by men, namely, physical, sexual, and emotional abuses and controlling behaviours, including attempted and completed homicide, perpetrated by a current or former date, boyfriend, husband, or cohabiting partner (with cohabiting meaning living together as a couple). Therefore, IPV and domestic violence are often used interchangeably (Alì \& Naylor, 2013: 373). Other terms are also used, such as: domestic abuse, intra-family violence, wife abuse, spousal abuse, wife battering, dating violence, courtship violence, battering, violence against women and intimate partner abuse (Gerberding et al., 2003). 
he will associate, and how they will behave with him or with her in return, the degree in which each will be able to establish and maintain a mutually rewarding relationship Bowlby (1973b: 24). In other words, they greatly determine the partner's choice processes as well as the quality (stability, instability or dysfunctionality) of relationship itself. On this line of thought, Structural Coupling $\mathrm{Hy}$ pothesis assumes that everyone chooses a sentimental mate with an attachment configuration compatible with its own (structural coupling). Security degree regulates the whole process: secures subjects would be pushed to choose one another (similarity hypothesis and security hypothesis), and, consequently, insecure subjects would be pushed to join with partners who have an insecure attachment style but complementary to their own (complementary hypothesis).

Hence the idea of a discriminating factor between normal couples and pathological couples.

Intimate partner violence relationships, dysfunctional relationships that which are similar to a "predator-prey" rapport (Bartholomew, 1990; Byng-Hall, 1991), are the result of interaction between complementary personalities declined in the direction of the structural coupling between an insecure/avoidant partner (the abused victim) and an insecure/ambivalent partner (the abusive one). The victim's avoidant personality explains her selection of an ambivalent partner, in need of affection, albeit anxious of being abandoned, and, for these reasons, controlling. As some studies have shown, this type of partner "feel particularly vulnerable to the potential loss of an attachment figure and may strike out violently in order to regain proximity to an intimate partner" (Henderson et al., 2005: 219; see also Bartholomew et al., 2001; Dutton \& Golant, 2008). He is able to trigger interaction processes leading the couple into a pathological abyss, into

\footnotetext{
${ }^{2} \mathrm{An}$ ongoing search for risk factors characterizes current literature on Intimate Partner Violence $(I P V)$ against women. Many explanations for understanding the causes of IPV and its risk factors have been proposed, including biological (brain injury, neurochemical mechanism), psychological (abusive partner's mental disorder, depression, personality disorder, attachment problems, low self-esteem, excessive or weak assertiveness, communication difficulties, and poor problem solving skills), and sociological explanations. Sociological theories of intimate partner violence seek to explain violent behavior as a function of cultural and social structures, of social conditions and forces allowing and even encouraging the victimization of women by men (patriarchal socio-cultural structure, sexism, socioeconomic resources, status inconsistency), rather than individual psycho-pathology. For example, for Family Violence Theories (Family Conflict Theory, Ecological Theory, Resource Theory, and the Subculture-of-Violence Theory) intimate partner violence is the result of conflict within the family that can be explained as reaction to "socially structured stress" and institutionalized socioeconomic inequalities (e.g., low income, unemployment, poor health) (Larsen, 2016: 17; Gelles, 1999). Feminist Theory sees intimate partner violence as an expression of a socio-cultural patriarchal system which culturally legitimates men's domination and control over women, favouring socially their economic subordination and their exposure to IPV (see also Dependency Theory). Resource theory confirms the role of patriarchal ideology: men who have fewer resources (e.g., education or income) as compared to their female partners are more likely to use violence to re-establish their control within the relationship (Larsen, 2016). Psychological perspective on IPV focuses on various factors that affect the individual perpetrator or victim, although research has focused predominantly on male perpetration. There is some evidence of an association between attachment anxiety and perpetration of violence (Dutton et al., 1994; Babcock et al., 2000, Henderson et al., 2005). In general, researchers agree to consider IPV due to interaction of multiple factors at the individual and societal levels, and to require a multifactor explanation approach (Rodriguez-Menes \& Safranoff, 2012; Heise, 2012).
} 
the quicksands of a relationship where a rigid complementarity traps the victim into a position of dangerous subordination in respect to her persecutor, who holds an active, dominating position.

As already said partners' personality structure is the predictor of partner choice and victimization risk. A secure attachment style for victims is a protective factor from the risk of victimization unlike an avoidant attachment style.

Given this, a first consideration comes from studies that within the context of behavioral psychology have attempted to empirically support the psychological determination of partner choice and structural coupling hypothesis. In this regard, although the most valid instruments of analysis in this field, starting from Hazan and Shaver's ones (Hazan \& Shaver, 1987), have been used, results have not been univocal. Doubt remains that the personality structure is not the factor that greatly determine partner's choice and that other factors can come into play in a significant way.

In this regard, sociological reflection, for example, has opened interpretive horizons in which the orientation of sexual attraction, the physical traits as well as qualities to be sought in an partner in order to deserve to him the selection to get in the couple relational circuit respond to socio-cultural expectations as well and not just to psychological personality needs or bio-psychological evolutionary instances. Love "exists" or is it a simple an evolutionary deception, a useful strategy to favour reproduction and survival of the human species that has improved by evolution? Does our mind "deceives" us, by filling of sentiment what is just an evolved instinct to biological, sexual, reproduction and survival, or an evolved primary need of attachment useful to survival of human species? Evolutionary bio-psychology perspective is inclined towards these second alternatives. Evolutionary psychology research is in line with argument that evolved mate preferences exist (for men, physical attractiveness, and fertility; for women, social stability and economic security above traits relating to fertility and physical appearance), and showed stable sex differences in long-term mate preferences, in line with an evolutionary framework (Buss, 1989, in a comparative work which has now become a classic in this field; Davis, 1990; Buss \& Schmitt, 1993; Miller, 1998; Shackelford et al., 2005; Boxer et al., 2013; Bech-Sørensen \& Pollet, 2016)³. However, if this can be true, it is also true that culture has given meaning to love, whatever love is. In this sense, partner choice does not take place in a vacuum. How and with whom we form intimate relationships, what we expect from the relationship, reveal social constructions as well, cultural expectations being subjected to synchronous and diachronic variability, among societies at the same time and in the same society over time, and to learning. In the mid-1980s, mul${ }^{3}$ Findings of evolutionary psychology research are in line with the argument that evolved mate preferences exist. Some studies have also highlighted that these preferences are likely malleable to socioeconomic temporal trends. They have suggested that the sex differences in mate preferences might be becoming smaller as a consequence of increased gender equality (e.g., Kasser \& Sharma, 1999; Zentner \& Mitura, 2012; Buss et al., 2001) and found that men and women's preferences converged from 1939 to 1996 towards similar preferences for physical attractiveness, financial prospects, and mutual attraction. Nevertheless, stable sex differences in long-term mate preferences in line with an evolutionary framework were found (e.g. Bech-Sørensen \& Pollet, 2016). 
tidimensional models began to emerge where intimate relationships were perceived not only as a fusion of the couple's emotional and physical characteristics but also as "an experience interacting with different systems" (Shalev, Baum \& Itzhaky, 2015: 2). Research has given space to cultural and social context and to family system (family social network), as factors in mate selection process, investigating societies in transition from traditionalism to modernism (e.g. Surra \& Huston, 1987; Cate et al., 2002; Uskul et al., 2007; Zhang \& Kline, 2009; Nesteruk \& Gramescu, 2012).

New problems have opened up.

Whereas, in more traditional societies, socio-cultural institutionalized criteria regulate mate selection processes (social criteria of class membership, ethnicity, religion...), in modern society, functional and symbolic differentiation has increased the variety of elements which can be selected in the decision-making interaction process concerning partner's choice. Mate choice is became a matter of free, voluntary, choice, starting by romantic love, with its ideals of a endless and stable relationship, and its expectations of a partner able to complete us. Nevertheless, does "romantic love" exist even today? Is love as relationship still important in our lives? How are couple expectations structured from post-modernity? Today, what do we look for in our partner? In Baumanian interpretation of post-modern intimacy, fragility of current intimate relationships redefines the rules of the game, narrowing and shading the boundaries of the couple expectation field. Contrasting with Bauman, for Beck contemporary love is still understood as an antidote to social isolation, basically continuing to preserve and cultivate certain traits of romantic love complex (the continuous search of own self in you, the sense of mutual commitment, sharing expectations, mutual sentimental and sexual confidence, albeit it is actualized in terms of equality and negotiability of the forever).

If we consider the current state of knowledge, the only thing which seem to can be said is that the partner's choice is a place for confluence of emotional, psychological, cultural and social factors in forging the couple expectations, but there is no certainty on the conditioning or impact strength of these factors, on the way in which they interact. In other term, uncertainty concerns the possibility of choice predictability.

A second consideration concerns the fact that Structural Coupling Theory assumes linearity to a process, mate selection, which instead reveals to be nonlinear. First, from a theoretical point of view, this consideration concerns the statute that contemporary epistemology attributes to linear determinism and to the category of predictability in itself parallel to a change in the system concept as complex adaptive or evolving system.

In the light of the most recent theoretical and methodological acquisitions in the field of complex systems, the present essay attempts to re-read mate selection process compared to Structural Coupling Hypothesis and in so doing reflects on victimization risk in intimate partner violence.

Using the Complexity perspective, it assumes the couple as the emergent re- 
sult of a interaction system between agents engaged in a mate choice decision-making process in modern society, which is based on the interplay of a variety of factors whose outcome is neither determinable nor predictable. We propose that adaptive complex system and non-banal machine concepts are more effective to understand the mate selection process than linear deterministic approach, which appears too mechanistic for a process that shows to include an inextricable dimension of uncertainty and unpredictability. This does not mean a leap in the limbo of randomness and inexplicability, as the system responds to the input of various factors (biological, psychological, social, cultural factors...), and the whole choice process can be referred to an explanation order. But it means recognizing that the system responds to external and internal inputs by autonomy, works as a non-banal machine, and, in doing so, can produce emergence, uncertain and unpredictable outcomes and scenarios. Therefore, while not excluding the possibility of a deterministic interaction structure between partners, the paper places it in the framework of a nonlinear determinism allowing that all outcomes, any structural coupling, any choice, are possible and, consequently, surprising and unpredictable, being dependent on unknown and unknowable initial conditions. As a result, referring to intimate partner violence, this means a change of perspective than Structural Coupling Theory: if any structural coupling is possible, this means that victimization risk can be distributed among all women, independent on attachment style. We should think of this experience as an event that can happen not only to one type of woman but to all women: any woman (secure, avoidant, or ambivalent) today, may be the victim of tomorrow. This introduces the theoretical and practical significance of the present contribution.

On the one hand, it intends to clarify. In virtue of the reasons above stated, from a theoretical point of view it would intend to question the possibility to circumscribe the victimization risk to a victim's type, which means to postulate that there are women being in a certain extent predestined to become a victim due to their personality structure. On the other hand, this theoretical interest has repercussions on practical social significance of the present contribution with reference to prevention issue. If from a theoretical point of view this perspective may appear more democratic, less prejudicial than structural coupling hypothesis, from a practical point of view it is certainly more alarming. From this point of observation, there would be no personal resource able to exert a preventive function: personal security is not a reservoir of resources to which a woman can draw upon to protect herself from the risk of being victimized. Vulnerability appears absolute and general, and victimization risk imponderable.

In order to verify these assumptions, the paper used as reference point a sample of 100 IPV victims, which was selected by the help of several Italian anti-violence centers and voluntarily accepted to take part in the study. Although without advancing any inferential claims (for obvious reasons, the subject matter does not lend itself to favor the building of a representative, random, sample of 
victims of gender-based violence), according the structural coupling hypothesis we should expect that the sample's victims are women with avoidant attachment style. Otherwise, we expect a wide heterogeneity of attachment styles. The analysis used Hazan and Shaver's classical tools to detect the attachment styles, and Faces III (Olson, 1985) as an additional control tool, in the hypothesis that the attachment style and the degree of security of individual personality is positively correlated with the degree of internal cohesion and flexibility of family system of origin.

By looking at the most recent sociological reconstructions of intimacy in post-modern society, at the way modernity would have restructured intimate relationships and couple expectations, the analysis become also the opportunity for investigating the role of cultural factors in mate selection processes of sample's victims.

At this point, we must retie the threads of the discussion starting from Bowlby, and from the aspects of his intellectual background that appear fundamental to our discussion.

\section{Theoretical Background}

\subsection{From Behavioral Attachment System to Structural Coupling}

Intimate attachments to other human beings are the hub around which a person's life revolves, not only when he is an infant or a toddler or a schoolchild but throughout his adolescence and his years of maturity as well, and on into old age (Bowlby, 1980: 442).

Attachment Theory concerns the role that close emotional bonds that people develop towards others, most notably parent and romantic partners, play in our lives, how they develop, and how primary attachment history affects personality structure and its development, human experience and behaviour, interpersonal and emotional functioning in adulthood (Gillath et al., 2016). The desire of interpersonal attachments, of warm and supportive relationships with someone who understands us and advocates for us is for Bowlby an essential human desire, in childhood as well as in adulthood, as manifestation of an instinct that evolved originally to ensure the child's safety and protection, and ultimately his or her reproductive fitness. It was ethology that allowed Bowlby to consolidate the scientific foundation of his theoretical construct contrasting the official psychoanalytic theories of the early $20^{\text {th }}$ century, which reduced emotional ties with the mother, or, to the caregiver in general, to merely a secondary drive compared to primary nourishment needs. Lorenz' ethologic studies (Lorenz, 1949) on imprinting and those of Harlow \& Zimmermann (1959) on the Rhesus Macaque monkeys, provided Bowlby with a scientific base for generalizing the idea of a behavioral attachment system, of a complex constellation of feelings, emotions and behaviors, understood as evolutionary expression of a natural, primary need for the creation of emotional ties irrespective of nourishment need, in order to optimize survival possibilities. What constitutes the theory's distinctive and original aspect is the bio-social character of the attachment process. 
From this perspective, for Bowlby, ethology is the meeting point of evolutionary biology with cognitive-behavioral psychology, that is, the meeting point between the biological, objective, dimension, consisting in the child's innate propensity to establish and prioritize an emotional personal bond with a specific care-giver figure among many (monotropy), regardless of mere satisfaction of hunger and thirst, and the psychological, subjective, dimension of an attachment pattern, originating from the configuration of interaction models acquired in primary infant relationships, and susceptible to influencing the organization of personality and guiding and orienting future adult relationships. In this sense, the attachment style that individuals construct in infancy is no other than a property of the primary relationship, strictly dependent on parental care dynamics to which one was exposed, with internal working models (cognitive maps or self representation models and one's own social word) being molded in a complementary way based on how well the caregiver is able to provide adequate care and support, and conceived, in this particular sense, as "internalizations of primary relations of attachment" (Loriedo \& Picardi, 2000: 239). For example, for Bowlby, a warm and supportive relationship provides people with a sense of security, facilitates their positive personality, social and emotional development, and favour a positive representation of self and others (Gillath et al., 2016: 3).

The crucial aspect is, therefore, the accent placed by Bowlby's Theory on relationship, and not only because the theory is enucleates starting from the attempt to understand the attachment styles and working models by reference to family interaction systems to which individual belongs and not by observation of the single individual behavior, being mother or child (Collins \& Reed, 1990), but also because the emphasis is placed on their possible repercussions on whole individual relationship life. Understanding interpersonal and emotional functioning in adulthood requires, for Bowlby, understanding the person's attachment history. In a 1977 article, Sroufe \& Waters (1977), found in the organizational construct concept, the most suitable synthesis for explaining the function of self and others mental model. They, linked to phases of Piaget's cognitive development (Piaget, 1936), work as cognitive maps in orienting self representations and of one's own social world, evaluating situational alternatives, generating expectations and forecasts about others' behavior and one's own relationship life, programming possible optimal responses, in situations of need and anxiety above all. But, even more important, they are conceived as stable interpretive patterns, working as linking or continuity mechanism between attachment in early childhood and relationship life in adulthood ${ }^{4}$, and organizing and guiding in a consequential way affections, evaluations, knowledge and behavioral responses in the most diverse situational and relational social setting:

[..] the kinds of experience a person has, especially during childhood, greatly influence both whether he expects later to find a secure personal base, or not, and also the degree of competence he has to initiate and maintain a mutually rewarding relationship when opportunity offer. [....] the 
nature of the expectations a person has, and the degree of competence he brings, play a large part in determining both the kinds of person with whom he associates and how they then treat him. Because of these interactions, whatever pattern is first established tend to persist. This is a main reason why the pattern of family relationships a person experiences during childhood is of such crucial importance for the development of his personality (Bowlby, 1973b: 24; 1979: 104).

Through the prerequisites of attachment model stability during time and the persistence of primitive MOIs, able to act as ensuring mechanism for continuity attachment patterns, Bowlby's Theory provides a prominent reference framework for understanding personality processes and all close individual relationships, including romantic relationships.

Even romantic relationships function as attachments. In the words, attachment system underlies adult romantic loves. Even in adulthood, people have a need to belong (Baumeister \& Leary, 1995: 497), a desire of warm and supportive relationships providing "feelings of safety and security, and without them people feel lonely and restless" (Gillath et al., 2016: 13). Even "adults show a desire for proximity to their attachment figure when stressed, increased comfort in the presence of the attachment figure, and anxiety when the attachment figure is inaccessible" (Gillath et al., 2016: 13). But, more importantly, the nature and quality of one's close and intimate relationships in adulthood are strongly determined by affective events that took place during childhood (within the child-caretaker relationship). In adulthood, in highly emotional sentimental relations like romantic ones, the same primary interaction models are reactivated. Early Attachment styles and the primitive MOIs govern our expectations and predictions on the possible structure of intimate relationship, determine the development of specific partner models and of the romantic relationship, and determine the amount of gratification emerging from the interaction between attachment styles of the partners (Collins \& Reed, 1990; Reed \& Miller, 1989).

Whereas Bowlby concentrated primarily, with Ainsworth, on the study of the nature and working of primary relationships, in order to classify attachment styles into secure, insecure-avoidant, and insecure-ambivalent types ${ }^{5}$ (Ainsworth et al., 1978; Ainsworth, 1989; Ainsworth \& Bowlby, 1991). Hazan \& Shaver (1987) were the first to investigate the life-long stability of early attachment styles and their capacity to influence romantic relationships. By using analysis instruments able to translate infant attachment patterns described by Ainsworth into the most appropriate terms to grasp attachment in adulthood, one of the enduring ${ }^{4}$ The internal working model construct is central in Attachment Theory, highlighting the role that early experiences play in shaping attachment style and personality development. It explains the developmental antecedents to individual differences in basic personality traits, political ideology, social acceptance, and aggressive tendencies. The working models provides a means to describe the kinds of difference that exist, while also providing a "means to understand how they come to exist and are sustained across time" (Gillath et al. 2016: 13). This explain why Attachment Theory is so central in modern research on personality development and clinical psychology, Indeed, for Bowlby even the development of psychopathology find potential risk factors in disruptions in attachment-related experiences and their internalization via working models (Gillath et al. 2016). 
contribution of Hazan and Shaver work was the investigation of the idea that the same kinds of individual differences that characterize infants in the strange situation (secures, avoidant and ambivalent children), also characterize the way adults approach close relationships. They classified secure adults, that are comfortable to opening up to others, using others for support, and having other depend on them, insecure-avoidant adults, which have difficulty to opening up to others, and, in many cases, they avoid intimacy, as a way to prevent themselves from feeling vulnerable, and insecure-ambivalent adults, which can desire closeness and intimacy, but, being insecure, are excessively clingy and prone to loneliness (Gillath et al., 2016: 14).

This line of investigation is focused on the structural coupling concept. A fundamental role is played by the attachment style both during the relationship itself, on the process of maintaining the relationship, by influencing its quality and duration (stability, communication quality, degree of trust and level of mutual satisfaction), and during the initial phase of attraction, on the processes of mate choice and couple formation, by encouraging the selection of partners who have expectations and fears regarding interpersonal relationships compatible to their own, according the their attachment style (e.g., Hazan \& Shaver, 1987, 1994; Collins \& Reed, 1990; Feeney \& Noller, 1996; Simpson, 1990; Hazan \& Zeifman, 1999; Banse, 2004; Simpson \& Rholes, 2015). In other words, the theory leads us to assume that individuals bring their own stable behavioral models into their intimate relationships, and that these are then adapted to the partner's behavior style, each one seeking a mate to whom his/her own attachment style is ready to respond (Weiss, 1982). And above all, as mentioned in the introduction, the theory leads to expunge randomness from the mate selection and the couple formation process, which is subordinate to the activation of the structural coupling process between partners' attachment styles (Loriedo \& Picardi, 2000; Loriedo et al., 2011).

But what are the structural coupling mechanisms? And what are the implications?

Including Hazan and Shaver's studies, a noteworthy theoretical effort has been addressed toward defining the contents of adult attachment styles and the terms of their compatibility.

On one hand, the dimensions of adulthood attachment styles able to influence romantic relationships and their corresponding internal working models have ${ }^{5}$ Mary Ainsworth drew up the so-called Strange Situation protocol, a standardized lab procedure to study and classify mother-child interaction schemas in early childhood. The Strange Situation is a twenty-minute mini drama where child behavior and its emotional reactions are observed in the mother's presence, at the moment of separation and at reunion time. Ainsworth divided the child groups into three categories: the first group manifested positive feelings toward the mother, the second group had non expressive, indifferent or hostile relations with the mother, and the third group showed markedly ambivalent relations. The infant attachment styles were classified in the secure, insecure-ambivalent and insecure-avoidant typologies, according to caregiver ability to be responsive to needs of their children, emotionally available and materially supportive in exploration (see also Main et al., 1985; Main \& Goldwin, 1995; Crittenden, 1992; Stevenson-Hide \& Shouldice, 1995). It is within this framework that expressions like personal sure base and family security make sense, due to the precious work of the empirical research conducted by Bowlby together with Ainsworth (1989). 
been theorized to run on the intimacy-avoidance-relational anxiety axis for the attachment style; positivityl negativity for self or other's mental models; and accessibility-responsivitylirresponsivity for infant care-giving attachment figures (Hazan \& Shaver, 1987, 1994; Collins \& Reed, 1990; Bartholomew \& Horowitz, 1991; Shaver \& Hazan, 1992; Holmes, 1993).

Going into more detail, while referring to these dimensions, a positive model of self (with high self-esteem, trust, independence, self-assurance, expressive ability, such as to manifest altruistic love) and the other (as trustworthy, selfless, able to control the course of his life) identifies a secure attachment style, also characterized, as we said, by a high degree of appreciation of intimacy and closeness, a low level of avoidance (or emotional detachment) and low level of anxiety coming from fear of being abandoned and not being loved, and promoted by infant experience centered on emotional availability and responsivity of the principal attachment figure of reference. Insecure personality structuration is otherwise. The insecure individual classification is doubly articulated since it is related to the experience of cold and inconstant or rejecting childhood attachment figure. Specifically speaking, the rejecting attachment figure generates individuals who have avoidant insecure attachment style, that is, individuals with a positive self-model and a negative model of others, who do not appreciate proximity and intimacy and who prefer keeping a certain emotional detachment (high avoidance), reluctant to nurture trust in the availability of others, without any particular fear of being forsaken (low anxiety) and fluctuating between need/fear of closeness and autonomy. Instead, a negative self-model together with a negative model of others identifies the insecure anxious/ambivalent style, promoted by inconstant infant attachment figures which tends to generate personalities divided between intimacy appreciation and fear of being abandoned and not loved, with little self-esteem and trust in oneself and in others. In this case, there is higher probability of manifesting an obsessive/dependent and controlling style of love. At this regard, as Henderson emphasized, there is evidence of an association between attachment anxiety and male intimate violence (Henderson et al. 2005: 221): in clinical and not clinical samples, violent or assaultive men were less secure, "more anxiously attached to their wives, needing more nurturance from their wives, and more jealous than non-violent men" (Henderson et al. 2005: 221, with dysfunctional personality traits such as anger, Borderline Personality Organization, and trauma; see Dutton et al., 1994; see also Holtzworth-Munroe et al., 1997; Kesner et al., 1997; Babcock et al., 2000; Dutton \& Golant, 2008). In other terms, intimate abusiveness was found to be the product of unentire constellation of dysfunctional traits of personality rather than an isolated behaviour (Henderson et al. 2005: 221; Dutton et al., 1994: 17).

On the other hand, the line of conjunction between the behavioral attachment system and structural coupling is short, being that the structural coupling concept connects to the similarity and complementarity hypothesis of attachment models (Gillath et al., 2016). 
Proceeding in this direction, the theory's first and most immediate implication, in fact, is the creation of a marketplace of intimate romantic relationships where secure subjects tend to choose secure partners, while, consequently, insecure individuals tend to join up with subjects endued with an insecure attachment style but complementary to their own style (avoidant subjects with anxious/ambivalent partners and vice versa). For anxious or ambivalent men and women, it is not easy to undertake relations with partners sharing their own worries of being abandoned or not being loved. Whereas, it would be easier for them to relate to a partner with a complementary style: somewhat low anxious and insecure/avoidant. In turn, avoidant subjects are more likely to link up with anxious/ambivalent partners, more needy of affection with low avoidant attachment styles, rather than with those who are avoidant as well.

Secondly, based on these premises, the structural coupling connects straight to the stability or dysfunctionality issues of the intimate relationships, referring it to the relational experience between insecure partners, which are more liable to entertain unsatisfactory relationships, with dangerously wavering reciprocal feelings of trust, and, consequently, with more easily conflicting and de-stabilizing relationships than couples with secure partnerships (Collins \& Reed, 1990). In particular, fertile terrain for dysfunctional couple bonds, where conflict assumes a pathological turn, is considered the interaction between an avoidant partner, who is the abused, and an ambivalent one, the abuser. This type of relationship traps the victim in an obsessive, often tragic epilogue, relationship, which constitutes a "predator-prey" rapport (Bartholomew, 1990, 1993; Byng-Hall, 1991). Bartholomew (1993; 1997) suggested that mating choice according to structural coupling works to confirm one's self perception and the perception of other and to justify the repetition of own relationship models. So, from this perspective, the ambivalent would find confirmation for his fears and insecurity and justification for his emotional dependence on the detachment attitude of the avoidant.

What about the empirical plane?

On empirical grounds, till today, the similarity/secure and the complementarity hypothesis has not achieved univocal results. On the one hand, there are some studies where the structural coupling hypothesis among secure individuals seems to have been confirmed, with little proof of romantic relationships which are characterized, even at the level of preference, from anxious-anxious and avoidant-avoidant coupling in respect to avoidant-ambivalent coupling (e.g. Collins \& Reed, 1990; Kirkpatrick \& Davis, 1994; Pietromonaco \& Carnelley, 1994; Holmes \& Johnson, 2009; Strauss et al. 2012). On the other hand, other studies have shown inconsistencies in respect to the theory. For example, secure subjects coupled to anxious partners (e.g. Brennan \& Shaver, 1995), and anxious or avoidant subjects related with similar partners (they too, anxious or avoidant respectively) (e.g. Frazier et al., 1996). Furthermore, there are insufficient studies on the issue of the avoidant/ambivalent coupling in the dysfunctional relationships. Although we cannot exclude that the attachment style can influence 
on-going relationships, as far as quality or degree of satisfaction is concerned, the question whether it is a preeminent, determining factor in selection partner process is still substantially open to debate.

In this regard, it is possible to find some tendency to closing the question by reducing the structural coupling to a matter of higher frequency of certain combinations in respect to others (e.g. see in Loriedo \& Picardi, 2000). Nevertheless, from my point of view, the risk is that the whole approach can acquire, behind the screen of "a general possibility of every combination", the status of a metaphysical theory in Popper's sense of the term. What seems certain, however, in this state of affairs, is that the non-uniqueness of the findings brings the theory to a serious confrontation with the possible impact of factors whose role it has strongly downsized, as in the case of sexual attraction, or disregarded, as in the case of cultural factors, and to a re-thinking about the way in which attachment can relate to these other factors.

About that, in Bowlby's epigenetic model, the role played by sexual attraction in the formation of couple ties loses the preeminence it has within the biological evolutionary approach of classic Darwinism derivation (Buss, 1989; Buss \& Schmitt, 1993; Bech-Sørensen \& Pollet, 2006). The quest for intimate relationships is not activated by atavic/ancestral, natural, and biological exigencies, being functional in terms of adaptation to the project of maximization of the reproduction, but primarily by the need for attachment which is the expression of safety and emotional stability needs (Shaver et al., 1988; Weiss, 1982; Holmes, 1993). By assimilating intimate relationships between adults to primary relationships, the theory locates, therefore, the essential criteria for guaranteeing both the building of intimate ties and their endurance in time in the component of safe base of the couple relationship and the ability of partner to provide comfort and care. Sexual attraction, although it is necessary, is not considered a sufficient and primary element. This aspect is became one of the major criticisms to the Attachment Theory. Several studies have shown that many romantic relationships begin not because people happen to find themselves attached to someone, but they often begin to mutual physical attraction or sexual interest. All this, therefore, led to rethinking the role of attachment, more in the line of an intersection between attachment and sexuality in close/intimate relationship (Gillath et al., 2016).

As well as it is about re-thinking about the cultural factors role in selection partner process and how attachment can relate to them as well.

\subsection{From Structural Coupling Theory to Social Construction of Intimacy}

\subsubsection{Transformations of Intimate Life: Romantic Love}

As we have seen above, the theory of Attachment Style resolves certain questions concerning formation and maintenance processes relating to intimate relationships within the framework of early childhood biographies.

Nevertheless, modalities of expression and achievement of intimacy respond 
to social values and normative structures as well, to symbolic institutionalized codes which define contents, orientation modalities, choice limits and even the conditions of their own existence. In other terms, how and with whom we form intimate relationships, the qualities to be sought out in an other in order to form a couple are a social construction as well They reflect a social and cultural process which is subject to synchronic and diachronic variability. It informs processes of love's meaning production, expectations which are connected to the way to conceive the couple, the intimate relationship formation and stability, and implies the learning dimension and socialization process.

Proof that the structure of intimacy can be referred to a social construction is, in fact, the profound change of significance that has invested the sphere of romantic relationships during the transition from pre-modern to modern times throughout Western societies. The same concept of intimacy is a product and a primary characteristic of modernity, which enters into that larger framework of social and cultural transformation due to the advent of Industrialization (differentiation of functions and interests, pluralism of values, weakening of shared common traditions and transcendental foundations of social solidarity). Therefore, the intimate relationship profiling runs parallel to modern processes of individualization, and to the re-structuration of the tie between community (Community-State, Community-family, Community-Church) and the individual, between common good and individual good, between responsibility and freedom, which is ever more unbalanced toward the latter term of the binomial, moving from the holistic tie connotation, typical of traditional societies, to the new, modern, form of atomistic tie. Progressive de-traditionalization of vital worlds, referring to family and conjugal relationships, intervenes, in fact, to activate a process of profound re-structuration of intimacy which consists in the emergence of a love conception as convergent love (Giddens, 1992), that is, a contingent, negotiable love, far from the "never-ending" and "the one and only" love of the romantic tradition, which, nonetheless, was its precursor, with its individualistic and subversive character, in so far as it implied freedom in choosing love partners.

Denaturalization of marriage and the traditional family, negotiability, instability and uncertainty of intimate life are, therefore, the scenario in which the postmodern couple's life is framed. The contemporary loves are liquid loves (Bauman, 2003), that is, fragile relationships, rendered uncertain by the absence of clear reference schemas, formerly ensured by tradition and by the "forever" institutionally enshrined. But what does this fragility mean in respect to the importance which love as relational modality has in our current life? What are the contents of the meaning of love today? What remains of the romantic ideals in modeling couple expectations which today lead to forming intimate relationships? Have they disappeared from the scene, weakened by the effects that romantic love itself helped to generate, shattered under the pressure of women's autonomy, of female sexual and occupational emancipation? Or, despite everything, do romantic ideals still persist in giving sense and content to couple rela- 
tionality?

This might seem a purely tautological question, the answer being implicit in the premise of the relationship fragility. Yet, among the interpreters of intimate relationship life there is no unequivocal position on this issue, whereas there is convergence of opinion in considering romantic love as the initial relational modality by which the process of individualization takes form in sentimental life. So, for example, in Bauman's interpretation, the Romantic ethos is part of our past more than Beck or Giddens are willing to acknowledge.

This reflection revolves, therefore, around the Romantic ethos and its destiny. Is it evanescent or persistent? What ideals, what sense connotations of intimate romantic relationships have been lost, or rather, are still conserved in making up the symbolic dimension of present day love?

Looking back to the process of intimate life transformation in modern society, it is known that the industrialization process has played an incisive role in reformulating old traditional structures: separation of family relations from the work sphere and the domestic community of origin; formation of the nuclear conjugal family and new intensity of sentimental expression among its components, and, most important of all, a new social and cultural legitimization of freedom of partner choice as condition for building marriage and family ties. All this is in direct opposition to the traditional duties of obedience to parental and kinship hierarchy and practical, socio-economic, raisons governing the formation of intimate ties, with a structure characterized mainly by a sense of duty toward the management of the household and family production business and by a cold relational formality.

The sociological reflection on postmodern intimacy converges in recognizing the nodal point of the new cultural framework forged by romantic love in the possibility of finally referring the justification of the couple union to the reasons of sentiment, such as basis of living together and proper framing of sexuality. One could say that the state of falling in love, so well described by Alberoni (1979) as the state of ignition that generates the couple, with that powerful sense of unity and will to renew the existent that assimilate the couple to a collective movement, becomes culture when freedom of choice is recognized as a social possibility, configuring the contents of what is usually termed complex of romantic love.

At this regard, the legitimization of freedom in partner selection greatly contributed in laying the foundation of a private life re-structuration process which is centered upon the concept of intimacy as mutual sentimental and sexual, emotional and communicative confidence, and as communion based on the sharing of feelings and intents, as mutual fusion of body and soul (Giddens, 1992).

Since the very beginning, highlights Giddens, due to its free choice foundation, romantic love has brought up the problem of intimacy, reformulating it into terms of psychic communication, better still, into a meeting of souls, that takes on the form of reparation. The emphasis on the reparation concept is relevant 
because it is the prelude to the grounding of romantic intimacy into a new and rich of individualistic connotations idea: the idea of seeking. The concept of reparation is, in fact, used by Giddens to allude to the close interpenetration between romantic feelings and the idea of the non negotiable searching of an other in whom one is able to recognize himself, that confirms and completes his own identity, repairing, absolving and solving those imperfections, those shortcomings, those feelings of emptiness that the love rapport renders insupportably discernable for the first time. It seems to be the prelude to a common biographical narration, forged by reciprocal dedication as principle directive of the couple life.

The concept of common narration discloses other meaningful points of clarification. Romantic love aspires to a common narration that connects the couple in their daily married and family life as primary objective and final stage of the relationship itself. This aspect appears to Giddens, for example, one of the most discriminating, when romantic love is compared to current convergent love. In the cultural framework of Romantic ethos, the reasons of sentiment and sex have finally been acknowledged, but kept under control, in their potentially subversive and transgressive nature in respect to rules and social obligations, through their association to the idea of marriage and maternity as crowning of the "search", and to the idea that, once found, true love is everlasting. Truth of love and its being forever are, therefore, the ideal expectations underlying the partner choice. In respect to love as passion, moreover, which was religiously banned from the social scene due to its disruptive nature of existing social order, the Romantic ethos linked love and sexuality together, and integrated them in an intimacy hooked up to a definitive nucleus of beliefs and ideals, characterized by transcendence, substantiated by the idealization of the love object and by the sublimation of feelings in their being "forever and timeless", beyond any possible temporal corruption. The everlastingness is rooted, therefore, first of all in the domain of aspirations, an aspiration toward an affective long lasting bond based on intrinsic qualities of the bond itself, of what Goethe called elective affinities.

Just on the intrinsic qualities of Romantic love, Simmel wrote some evocative pages. In the Simmelian interpretation, romantic love is qualified as ideal of strongly individualized love, contrasted with the abstractness of platonic love, and as dynamical process of construction of personal identity in the relationship with a partner of which the exclusiveness and uniqueness is considered (Fragment über die Liebe, posthumous publication, Simmel, 1921). As two partners' creative and transformative process, modern romantic love synthesizes, for Simmel, two exclusivities in unity and structures a relation modality whose traits are those of transcendence, of that timeless absolute able to challenge the intrinsic contingency of daily life, far from theologisms of sorts and lifted even to a supra-biological level, by nurturing itself on all those spiritual elements which are extraneous to essential material ones for the conservation of the species ${ }^{6}$. 
In these contents of romantic love we can recognize the conditions for a twofold social impact (Giddens, 1992): on one hand, the re-structuring of aspirations referring to intimate life, in particular of female expectations; on the other hand, the legitimization of traditional division of labour between the sexes, with the private domestic as pertaining only to women, and the consequential maintenance of the traditional asymmetry in the couple. Beck as well as Giddens emphasizes this aspect.

This would also explain why in many classic works emphasis was not placed so much on romantic intimacy as an autonomous study object, but on its functionality in consolidating family institutions, shifting interest on the conjugal family itself as basis of social order in its various functions: reproduction, social values transmission, identity construction, stabilization of adult personality and social integration. Thus, Durkheim (1921), for example, grasped the meaning of the new form of intimate relationship during the early years of modernity in function of the establishment of the family as stable and moral society, based on the cooperation between the sexes according to traditional division of roles. It was likewise for Comte (1864), for Tönnies (1887) and for Spencer (1896). Marital intimate life, with a virtuous rapport of affectionate exchanges of relational goods of care and protection, the sublimation of the wife and mother role, and stability ensured by marital legal bond, guaranteed the cohesion of the monogamous family, being the source of social harmony.

And if in Weber's interpretation of modern society (Weber, 1922) the end of the domestic community, transformed from productive unity to consumption unity by the emergence of rationalization process in the bureaucratic organiza-

\footnotetext{
${ }^{6}$ It is also interesting to note what developments Simmel's reflections assume from similar statements. Paradoxically, what constitutes the distinctive element of romantic love, for Simmel, also constitutes its most fragile point. On his reflection on modern romantic ties, the failure of marital unions lies, in fact, in that self giving without reserve that nurtures romantic love. In fact, Simmel sees modernity as an ambivalent process, which on one hand, creates new opportunities for freedom and autonomous self construction, but on the other hand produces, at the same time, insidious risks to the safeguarding of integrity and personal independence itself, and therefore, creates risks for the same constitution of self. Within intimacy, prime ground where we can show this ambivalence, the demand for fusionality, which the modern freedom of feelings produces, expresses the difficulty of the process of constitution of modern individual, which is always suspended between autonomy and dependence. In such a perspective Simmel's discourse on personal integrity defense mechanisms from modern social relation intrusiveness and pressure in intimacy as well as in friendship take on significant meaning. In reference to intimate relationships, a recurring theme into Simmel's theory returns, that is, the theme of reciprocal discretion as regulating device of social dialectics between unity/universality and individuality, as social action modality to protect individual personality integrity, and guaranteeing relational maintenance and development (Simmel, 1906). There is no doubt, for the author, that complete dedication and without reciprocal discretion in giving and receiving considerably threatens the future of the romantic relationship, which can last only if knowledge of the other does not runs out. Here lies the importance of reciprocal discretion, as antidote to boredom, to trivial and un-stimulating routine, to predictable relationships that have no longer space for surprise, or, in other terms, as a means to maintain ever alive the need to reciprocal discovery and interest in the marriage union. Thus, we understand why only those (very few, according to Simmel), who have a profound and rich inner life can escape from the rule, because they are able to be ever new and surprising by virtue of the inexhaustibility of the latent properties of their soul and the inextinguishable source of their spiritual life.
} 
tion of labor and production, is a prelude to the disenchantment of the affective world, it is still Parsons (1951) to emphasize romantic relationships as the foundation of modern nuclear family, a unity cooperative of two different but complementary and equal, expressive and instrumental, leaderships.

A contrast with the interpretation inspired by Marx and Engels (Engels, 1884) stands out. In the Marxian approach, it is impossible to live up to the romantic ideal in practice. This ideal is denied by the capitalistic productive system and private property, which strengthens the Patriarchy by maintaining women's economic dependence on men (for example, Hartman, 1976; Barret, 1988). The abolition of Capitalism is advocated as a condition for gender equality and a finally free and real couple intimacy.

Since the 70s, with the coming of the consumer society, much sociological literature has insisted on denouncing its adverse effects on personal identity structuration and on social relational life (for example, Lasch, 1977; Dizard \& Gadlin 1990). From this point of view, facing the general reification of life, consumer alienation and mounting cultural materialism, the Romantic love ideal appears opacified, and substantially weakened in the emotional content of expectations related to intimate relationships.

Significant anticipations can be found in radical Nihilism criticism against western civilizations by Adorno \& Horkheimer (1947). Man's reification, deprived of his time according to the dominant logic of progress-domain-labourconsumption, and the commercialization of relationships, valued only for satisfying the logic of utility and exchange, are thought to empty of meaning feelings and romantic ideals and intimate marital relations, by submitting them to the law of a cold utilitarian exchange between demand/offer of care and safety.

Even the current reflections of Hochschild (2003) tend to follow this line of thought that looks to modern man as subservient to the production-efficiencywork-consumption logic (Marcuse, 1964). What emerges is a picture of modernity, which is consolidated upon self-interest and instrumental quantification of every human sentiment that impoverishes the role of feelings and romantic ideals in post-modern man's relational life. In fact, the couple and family life is characterized by what Hochschild calls the commercialization of intimate life. The intrusion in intimate relationships of the capitalistic spirit and the market logic (conforming to criteria of success, efficiency, investment in production-work-consumption) relegates affectivity to unproductive times and involves the expansion to both sexes of a coldness culture, a culture of affective independence and emotional savings, of mistrust and affective disengagement, which induces modern society to turn to the market for care services which were previously provided within the family circle according to criteria extraneous to productivity and calculation logic.

In conclusion, is this colonization of intimacy by the logic of utility and consumption, this disenchantment and lack of affective commitment the coordinates around which postmodern intimate life revolves? Has Romantic love grad- 
ually evaporated? Has it finally reached the end of the line?

\subsubsection{What is Left of Romantic Love? Convergent Love and Pure Relationship}

The reversibility of choice and the fragility of intimate relationships, as consequence of development in individualization process, together with the shift of values axis from couple-system to the acknowledgement of the individual and his chosen freedom recurs in Giddens, Beck and Bauman's articulate analysis on relational intimate life in present day most mature modernity. Although they agree on how in recent decades the celebration of individual freedom of choice made negotiable what was not hitherto possible, their analyzes of the transformations currently investing the sphere of intimacy are not entirely converging.

The point of departure is still the same: Romantic ethos has cultivated reciprocal expectations for a relation with a partner who recognizes us a anique and exclusive being, willing to share reciprocal sexual and sentimental intimacy, sharing affection and intent, creating a fusion which does not mean total self-denial and, above all, ready to challenge time and space. What remains of all this, if anything at all remains, in the way we feel and live the post-modern intimacy? In our mature modernity, what criteria govern couple's relational expectations, thereby forging its formation processes?

In this regard, the answers, as we have stated, do not seem to converge entirely.

Currently, writes Giddens (1992), the ideals of romantic love tend to fragment under the pressure of female autonomy and sexual emancipation. According to the author, the current more mature modernity has brought to its most extreme consequences the potentially subversive nature contained in free choice as romantic love's foundation, by leaving entirely up to the single individual the relationship's destiny, its management and maintenance. In Gidden's interpretive reconstruction, intimate unions become fragile because of the feeling itself that first generated them, of the non-sense to continue a relationship when the communion that lies at its base dissolves. If, in such circumstances, in the universe romantic ethos, the marriage bond was still maintained in view of the family's common good, assured by the division of labor between the sexes and the social control through the matrimonial institutional bond and the values regarding women's respectability, today instead, aided by female emancipation, the prerequisite of free choice and the same reasons of sentiment have come to imply the unsustainability of a "forever" without love, eroding any constraint of moral and institutional obligation and favoring a type of intimacy constructed on the sentimental and sexual negotiability of the relationship, on a its continuous assessment based on mutual dialogue between equals. The present form of love, according to Giddens, i.e. convergent love, indicates, therefore the passage of romantic love into an active love, which modulates intimate expectations on the basis of a continual process of revision, and, for the same reason, an contingent, unstable love, fleeing from the idea of "forever" and "only and unique" 
love although it still retains the romantic striving towards the search for a full, mutual affective sharing and a confidant and fertile communication.

In this light, we comprehend why Giddens defines contingent love in terms of pure relationship. It is certainly not a matter of ideal purity but of a relational condition that is freely constructed in so far as the two partners believe to take advantage from a ongoing relationship with each other, remaining stable until both partners draw sufficient emotional gratification to justify its continuity. The more the romantic ethos still presupposed a strong asymmetry in couple and domestic subordination of women, the more pure relationship means sexual, sentimental and emotional parity, devoid of any constraints whatsoever. The lack of bonds, according to Gidden's interpretation, moralizes the relationship, purifying it from the incrustations of traditional constraints, yet, not meaning disengagement in the relationship itself. In fact, from this perspective, putting aside the ideal of "ever lasting", of which we can sense fragility, the social connotation of the pure relationship seems to be the expectation of a commitment without reserve, in so far as it is the only condition and possibility for a relationship to last.

The centrality of the ars erotica in intimate relationships constitutes, for Giddens, the real new element in the process of restructuration of the intimate sphere ${ }^{7}$. The plastic sexuality, as he calls it, is a sexuality freed from any reproduction constraint, gender stereotype, and the preponderance attributed to male sexual experience, and is founded on personal autonomy, moulded as an aspect of personality intrinsically tied to id and self-awareness, not necessarily oriented toward procreation, monogamy and stability.

This argument is not entirely new. Elias (1939), for example, had grasped this aspect by tracing the coordinates of a path where, without risks of extinction for humanity, intimacy associates with an eros (in the sense of combination of affective and sexual emotionality) which is freed from biological justification, and becomes increasingly a fundamental element for the constitution and continuation of conjugal relationships up to separation of conjugality and sexuality. Rather the problem is to grasp its implications for the stability of the relationship. And here, Giddens seems to move away from perspectives (such as Marcuse's one) seeing in a sexually freed from control and oppression of bourgeois morality, which confines it into the fence of monogamous marriage and subordinates it to generativity, the precondition for better, more civil and lasting relationships

${ }^{7}$ Giddens accepts the intuition of Foucault (1976) that interprets the emerging discursive explosion around the sexuality sphere as attempt to know and control already expressed with modernity by religious and Secular institutions, for a positive exercise of power, by building the bodies, desires and ways of life itself. And yet the theorization of Foucault would meet for Giddens a limitation in not having considered sufficiently the links between sexuality and romantic love as well as certain aspects of the modern individualization process on the sexual articulation of intimate life. From this perspective, the release of sexuality from traditional reproductivity constraints for material survival of family and community means for Giddens its progressively transformation into an individual's quality, in an ever individually malleable and moldable feature. In short, this is that ductile sexuality which is for Giddens the precondition for the sexual revolution of the last decades, as claim of a sexual permissiveness no longer neutral with respect to gender but extended to contemplate female sexual emancipation as well as that of male and female homosexuality. 
between gender. Otherwise, for Giddens, this new sexuality, to which dignity and reciprocal right of gratification are now recognized, and which, therefore, now enters into the net of negotiability, becomes a further ground for possible conflict and ulterior weakening factor in the relationship.

Love is moving toward this type of relationship for many sectors of the population, although not for everyone. But, how can we evaluate this process? What can we reply to critics, such as Bellah \& Madsen (1985), Gill (1997), Whitehead (1997), Popenoe (1992) who look with concern at the effects of the individualization process on intimate and family relationality, deploring current weakness of social ties and divorce culture and decreeing in apocalyptic tones the failure of a modernity whose rationalization instances would not keep their promises of progress?

These current changes in intimate life are, according to Giddens, revolutionary in a very profound way. Seen as negotiation of interpersonal ties on the part of equals, intimacy acquires a new value, becoming a democratic experience very much like democratic participation in determining one's own condition in the public sphere. Thus, convergent love, though it is the cause of our divorce society, would add value to intimacy by setting up the union on a continually renewed commitment, on reflexive bases, on the possibility of an equal and reciprocal dialogue, of a free, open and civil confrontation. On the one hand, by virtue of this democratization of the interpersonal relationship, convergent love would sublimate the value of the relationship itself. On the other hand, this experience of democratization in the private sphere could have a subversive impact on the social system, by favouring, like in a mirror game, a mature, respectful, democratic behavior in the public domain. Nevertheless, even the contradictions and the risks of a similar structure of intimate relationships do not escape Giddens, for example: increases in gender violence due to female emancipation pressure, the difficulty of finding a balance between a commitment without reserve, the one thing necessary today to keep up a relationship, and the risk of suffering much more in the future if the relationship is to peter out.

\subsubsection{Love and Identity}

The fact that intimate tie fragility is a product of modern life individualization is certainly not called into question by Beck. Yet Beck sees divorce increase, second marriages, and free forms of co-habitation as signs of a process that has made equally impossible and, at the same time, more important than ever love in our life (Beck \& Beck-Gernsheim, 1995 [1990]: 2). Hope of attaining love, of sharing life in two, has become the new center around which the tradition-free world of life revolves (Beck \& Beck-Gernsheim, 1995 [1990]: 3: our Italics), the last remaining of community that modernity has left individuals, now isolated in a society no longer supported by traditional ties

Even Beck's reflection as well as Bauman's one is focused on the dilemma between freedom/happiness and insecurity, which upsets human lives in the transition from pre-modern to modern. However, his analysis of the reversal of priority between family and individual biography comes to a different landing point. 
By introducing an ample individualization, developments that mark the passage into modern society (from the first industrialization with new labor market demands, geographic and social mobility, family nuclearization, up to work-market universalism and equality of the sexes, mass-media and consumer pressure $)^{8}$,

${ }^{8}$ In outlining these developments, Beck presents a two-step process, seizing the truly new aspect of individualization seen in the progressive disappearance of the feudal-like part of the first industrial society, with its gender based hierarchical order, ascribed birthright and sex ascribed roles, and the still traditional division of labor within the nuclear family context. The second step, starting from the end of the XIX century, was propagated to the detriment of counter-modernity (Beck \& Beck-Gernsheim, 1995 [1990]: 27). In fact, it represents the development of a process including, especially after the 50s and 60s, the extension also to women of the emancipation from traditional references and the acknowledgment of the right to build an autonomous biographical project, open to possibilities of the market, beginning from emancipation in the field of education and work.

Therefore, the real novelty was the progressive freedom of women from entrapment in private domestic sphere, the consideration of themselves no longer as family appendage but as individuals having self-fulfilling rights and wishes not solely dependent on the restricted identity of mother and wife, dedicating to the emotional labour, adapting to husband's wishes while sacrificing her own, nurturing no other wish than promoting family welfare. The old female role, self-denial for the sake of others, willingness to take on the endless and invisible emotional patching up, which was the adhesive for guaranteeing cohesion, has vanished (Beck \& Beck-Gernsheim, 1995 [1990]: 63). In unraveling the consequences of this development process, Beck shows its ending up straight into a corresponding increase of couple conflicts. When the cultural model of a self-projected biography, expression of the new generalized individualization, is applied to couple life, conflicts, clashes of interest, explode in private sphere, in all forms of marital co-habitation, before, after, and during marriage (Beck \& Beck-Gernsheim, 1995 [1990]: 24). So, from this situation the terms of a dilemmatic comparison emerge: either there is family and couple cohesion, enjoyed, however, under the old regime of female role and thereby paid at the price of women's inequality, or liberty and parity at the price of relationship stability; either there are female and male identities solidly anchored to unequivocal social models, or identities that can freely self-build and yet, because of the lack of definitive models, are unstable, fragmented identities, and with sensitivity towards ever new possibilities of re-definition among the many choice opportunities available that makes every form of intimate relationship uncertain and unstable.

And there is still another important consideration that makes Beck and that should be considered: the difficult reconciliation between love and liberation, that female emancipation involves, is not only the result of a more problematic deal between the desires of $t w o$ individuals, but rather of the "integralism" inherent to expectation of being acknowledged as individual who now models the way the woman conceives the union, in light of her new maturity, aware of the right she has to freely construct her biographical project.

When facing a relationship which, in substance, is far from being an union, adaptation and self-denial are no longer perceived as acceptable resolutions in principle, but, at least, as negotiable, to be freely chosen, possibilities. Therefore, it seems that the way delusions, the absence of a constructive dialogue, and the experience, ever more common, of being lonely and mis-understood are metabolized has changed significantly as a result of female individualization. If, in fact, in the past the only possibility for women, if they were disappointed, was to give up any hope of voicing their wishes, admitted that they perceived them at all, and in so doing to cling to their marriage, today, concludes Beck, women cling to their hopes and give up their marriage (Beck \& Beck-Gernsheim, 1995 [1990]: 62). The same is true for men, in their now new experience of finding limitations in their partner and of defending their own attempts to survive as an individual, as an independent being, within the shared life, those attempts which now dominate the couple life scenario for both partners (Beck \& Beck-Gernsheim, 1995 [1990]: 66).

It is thus understandable why bringing couple instability sic et simpliciter in the enclosure of biological or psychological explanations is according to Beck overly simplistic. Rather, the fragility of the intimate relationship, and even some current paradoxical psychological dispositions such as "it's no good with you and no good without you" (Beck \& Beck-Gernsheim, 1995 [1990]: 68), can be understood in the context of a socio-historical analysis, which historicizes its conditions as social phenomenon and not of nature, as product, especially at that stage that is extended to involve the female vital way, of individualization process and its contradictions, in having made love more difficult but also more important than ever, in having sown desperate need of liberty and yet, in the relational emptiness which the conquest of liberty has released, an equally desperate need of intimacy. 
break many of the bonds that tied the individual to his or her social environment and origins. They pulverize models of thought and behavior centering upon the common good, socially prescribed expectations regarding the sense of life, religious systems, collections of commandments and proscriptions geared to specify the right behavior, namely, the natural or prescribed by God behavior, in any situation (Beck \& Beck-Gernsheim, 1995 [1990]: 91). In so doing, they inexorably weaken integrative structures of family, kinship and faith community, where life choices were formerly formed, while they liberate social action from controls, constrictions and vetoes imposed on the possibility of building an individually chosen and projected existence. The individualization process, therefore, implies an individual and social loss of inner stability.

Freer but more alone, modern man lives a different and opposite condition to that of traditional societies where the plurality of ties inside of which the individual's life was articulated and molded, on one the hand, limited his freedom and choice possibilities, yet, on the other hand, offered him protection, security, a base of inner stability and identity able to safeguard him from isolation and loneliness and to make him feel forever safe and "integrated in larger unit" (Beck \& Beck-Gernsheim, 1995 [1990]: 46). Yet, and this is the focal point, according to Beck, these same social transformations even seem to have augmented hopes in a life shared by two and have amplified expectations of the couple life. In this sense, in the modern idealization of intimate life, Beck sees the direction of modernity (Beck, 1986; Beck \& Beck-Gernsheim, 1995 [1990]: 33). Without God, or family, or neighbors, without those traditional ties and patterns of life that ensure security, a protective context where one constructs the meaning of life and a solid identity, modern man seem to possess an ultimate, new earthly creed. The object of this new creed is all found in the phrase, "at least there is still You" (Beck, 1986; Beck \& Beck-Gernsheim, 1995 [1990]: 33), that Beck sees as post-modern reparation for that existential emptiness left behind by the unraveling of traditional ties ${ }^{9}$, last antidote to loneliness and insecurity in giving meaning to existence being induced by modernity, new foundation for identity building and inner stability. The more the traditional ties and patterns of life appear today to lose importance, other references of stability seem to be missing, the more the need to give meaning and anchorage to life turns to couple relationship. The size of You, says Beck, "is inversely proportional to the emotional void which otherwise seems prevails" (Beck, 1986; Beck \& Beck-Gernsheim, 1995 [1990]: 33).

Rather than indifference and disengagement toward sentiments, a new understanding of love is born. The model of long-lasting romantic love, the intimate sentimental tie between two people who have freely chosen each other, actually seems to give content and meaning to the actors' life who live through post-modernity. Contemporary love has not, therefore, abandoned the features of romantic love. The fundamental theme behind couple life is increasingly a matter of identity. In the face of pressing questions like who am I, why am I here, that we are presently called to answer as a consequence of modernity, love and identity are, for Beck, increasingly interwoven (Beck, 1986; Beck \& 
Beck-Gernsheim, 1995 [1990]: 51). Therefore, love still seems today to be a search: an unending search for a safe haven, for a solid You who completes a broken I, a perceived opportunity to build and confirm one's own identity by finding and mirroring himself in an other, and completing each another. In short, it is a seeking of one's self in the other. Love continues to cultivate expectations of authenticity, uniqueness, trust, sharing of intents, confidant sentimental and sexual communication, of an immanent priesthood for mutual unveiling, understanding, acceptance, absolution, redemption and conversion, for self-recovery and renewal, with the other and for the other in a new singular and transcending unity of creation. It follows another significant point. For Beck this love is, now more than ever, an idealized love. It is still tinted by the absolute; today love is more than ever exaltation, without any admission of compromise whatsoever, "religion after religion, the ultimate belief after the end of all faith" (Beck, 1986; Beck \& Beck-Gernsheim, 1995 [1990]: 12), and, in this form, it has become absolutely vital, and necessary (Beck, 1986; Beck \& Beck-Gernsheim, 1995 [1990]: 50). The search for romantic intimacy is even "the fundamentalist belief" of modernity (Beck, 1986; Beck \& Beck-Gernsheim, 1995 [1990]: 12).

Romanticism, therefore, would have won even today (Beck, 1986; Beck \& Beck-Gernsheim, 1995 [1990]: 12). And it wins as emergent effect of the process of individualization itself, the same process which is, at the same time, responsible for relational fragility. Outside those structures that, despite all, ensured a certain reliability and stability to marriage, outside the traditional control structures of the family and kin-ship and selective constraints of the same origin and status, outside rigid morality and division of roles and power of the nuclear family which still

${ }^{9}$ Accordance with issues (Bernard \& Schlaffer, 1981) is quite evident here. Pressing questions like who am I, why am I here, that we are presently called to answer as a consequence of modernity, appear to Bernard and Schlaffer more supportable if, in an empty cosmos, without God and where the work place is no longer really satisfying and meaningful, we have as point of escape and of source of existential meaning another person or persons with which one is willing to commit oneself to (quote from Beck \& Beck-Gernsheim, 1995 [1990]: 50). Therefore, against the backdrop of this empty cosmos, the construction of self and of the world become the central core of close, family and couple, relationships, the new meaning which intimate relationships acquire with modernity. Couple-life becomes the antidote against the risk of reducing own existence "to the frosty interactions of office life" (Beck \& Beck-Gernsheim, 1995 [1990]: 50), the forge where a common universe of shared attitudes, opinions and expectations referring to trivial day-to-day matters as well as to great social and political events, an image of the world and a self-image are molded by verbal dialogue and developed in shared habits and experiences. This shared image of the world is continuously negotiated, shifted, replaced, questioned and reaffirmed (Beck \& Beck-Gernsheim, 1995 [1990]: 50).

Beck shares this orientation as well. Couple life responds to our questions on identity. We search partner in which we mirror ourselves. We search him for complete ourselves. In this sense, for Becl love and identity are increasingly interwoven in our in post-modernity (Beck \& Beck-Gernshein 1995 [1990]: 51).

This common base of reflection will become the engine for an original analysis that fuses opposites in one unique existential reality, weaving into one destiny the hope for a couple life with the fragility of living together, the impassioned search for dialogue with the alter with the common experience of communication's frequent failure, of its stagnation, interruptions or total break down. Between hope and disappointment this intertwining of contrasting forces is, according to Beck, at the origin of a systematic renewal of a see-saw existential process which sees post modern man restart anew after every possible fall, every mistake sustained not being able to keep from renewing attempts, "to deterrer from trying again" (Beck \& Beck-Gernsheim, 1995 [1990]: 54). 
modeled, in an ascriptive way, life choice decisions in early modernity, life in two, between autonomous individuals, having their own desires and self-fulfilling demands and being oriented toward self-ruling their relationship and to a plurality of decision making processes always, however, revocable or negotiable, finds a difficult equilibrium. Indeed, parallel to the emergence of the new cultural model of a self-projected biography and to the process of radicalized self-government (Beck, 1986; Beck \& Beck-Gernsheim, 1995 [1990]: 194) that today individualism makes possible for couple life (the subjectivity and reflexivity feature of today's love, which gives itself its own rules), by having transformed love into a blank form (Beck, 1986; Beck \& Beck-Gernsheim, 1995 [1990]: 192) which the lovers have to fill and define and redefine autonomously, conflicts explode between two partners (Beck, 1986; Beck \& Beck-Gernsheim, 1995 [1990]: 14; 25).

In the difficult balance between two self-determined, with their own desires and instances of self-realization, individuals, involving in a plurality of decisions always revocable and negotiable and for which the rule is no longer the exercise of adaptation but the conscious separation or constructive disagreement (Beck, 1986; Beck \& Beck-Gernsheim, 1995 [1990]: 54), the writing of a common biographical narration has become an entirely individual and open to any solution matter. The narration work seems to be rather a diary, in which the two partners write the page of the day, restarting every time from there, without projecting the present in the future, with all the load of uncertainty that today burdens on tomorrow.

Beck's perspective closes around a couples-system that has become intrinsically unstable. It closes around the openness of love, subject to continuous individual verifiability of promised gratification, at any evolution outcome. The love story's development, the outcome of negotiability is not predetermined nor is it predictable. All possibilities are open and no one knows what will happen. According to Beck's words, love can be promising and conflicting at the same time; it can be everything and the opposite of everything: pleasure, trust, affection, hope and equally their opposites-boredom, anger, habit, treason, loneliness, betrayal, longing, jealousy, intimidation, despair and laughter (Beck, 1986; Beck \& Beck-Gernsheim, 1995 [1990]: 12-13), a tumultuous place of reckoning and attempts at fleeing, heavy and awkward silences, the loneliness of no longer feeling understood, deep and often unresolvable confrontations, those battles for self-realization of which a couple life seems to be the scene for both partners. Conflicts grow, and break up into a myriad of forms. Beck defines this situation as the normal chaos of love, because it is commonly experienced by all (Beck, 1986; Beck \& Beck-Gernsheim, 1995 [1990]: 3: Italics are ours $)^{10}$.

However, as was said above, the meaningful aspect of Beck's interpretation of post-modern intimacy is that one side does not exclude the other. The common-normal-difficulty of being together, of reconciling love and freedom, individuality and bond-ship, is the result of an individualization process which ends up going against itself, yet, this does not mean that love has lost its importance in our lives. Apparent contradictions would emerge from the very logic of individualization, of which Beck draws the intrinsic ambivalence, suspending men 
and women one toward the other and moving away from one another at a time. The fact is that, today, those who meet are two individualizations, two loneliness, two lacerations, and with so high expectations that a final landing is hard to find. Thus, conflicts, uncertainty and fragility of intimate relationships are inextricably intertwined with a longing for love and happiness that touches the dream and is promise of salvation from loneliness sown by the historical fragmentation of the community and social ties. Both are the sides of the same modern faith in love that embraces the worlds of life, individualized and freed from tradition.

Bauman's position appears to be, to some extent, more disenchanted.

Up to what point are we really motivated to load sense meaning to intimate relationships today? How much effort we are willing to invest in a relationship? Is the safe-haven of romantic love still yearned for? Per Bauman, it seems not

According to Bauman (1997) we are living in a liquid modernity, where a liquid love resides, a love relationship structured on ever-free re-negotiations. Looking at the risks and anguish of living together in our modern liquid world, close relationships seem, to our author, compromised by substantial ambiguity, authentic incarnations of ambivalence, complex and difficult balances, vacillating at freedom's call between sweet dream and horrible nightmare, without ever knowing when one will change into the other (Bauman, 2003). Bauman portrays a post-modernity made up of men and women with fragmented identities, anxious to establish intimate relationships, but, at the same time, even more fearful of remaining trapped in and caught up in stable relationships, fearing tensions, duties and moral responsibilities, which ultimately they are not willing to endure a sinker,

${ }^{10}$ The Beck's interpretation finds an objective correspondence just in today's structuration of socis systems deriving from the modern General System Theory (see paragraph 3). The non banality at tributed to systems behavior of the New Theory of Complex Systems, the concepts of self organiz: tion, emergence and surprise and of operational closure are particularly adaptable to his representa tion of the working and evolution mechanisms of intimate couple life, where couple-system shows $t$ behave like a complex system. From this perspective, the adjective 'complex' is used to represent th condition of systems which are in an intermediate position between complete order and complet disorder, on the edge of chaos, as it is usually defined, or, equivalently, far from equilibrium (entrc py). In this condition they are able to adapt to continuous external disturbance deriving from the en vironment, and they are able to continuously transform by self-organizing, producing ever new or ders, even if in terms of emergent, unexpected, surprising, unforeseen, and unpredictable outcome: as a macro result of non-linear micro interaction processes, among the system parts. This unpredic tability of possible scenarios corresponds to uncertainty of relationship outcomes which Beck de scribed.

By having liberated love from strong external traditional constraints, couple-system can behave like a non-banal machine: it autonomously responds to possible disturbances to its order, depending on its specific internal characterization, on the peculiarity of the partner relationships, and on the expectations and situated meanings that, from time to time, are exchanged and constructed. So, as Beck says, any outcome, any scenarios becomes possible and, therefore, unpredictable. Nevertheless, the often disappointing forms of self-organizing acquired by the couple relationship have raised, now more than ever, the problem of control of this free process. For example, according to Beck, this is the sense attributed to the constant rise of pre-nuptial contracts, that is, the attempt to entrust to the normativity of contract the regulation of possible sources of conflict, and to ensure in this manner to the intimate relationship that happiness and stability that love left to itself does not find. Is this a definitive solution? For Beck this seems doubtful, since the pre-nuptial contract mechanism implies making partner interests due and imputable (Beck \& Beck-Gernsheim, 1995 [1990]: 157). In substance, the above reasoning is fallacious. Rather, the pre-nuptial contract strategy and divorce seem to be doomed to reinforce each other. 
strongly limiting freedom to build and re-build one's own identity and to establish relationships. Post-modern social liquidity, for whom meanings, life-styles, careers and identities have ended up by becoming a project in progress (Bauman, 1995) continuously subject to re-definition, finds its manifestation of excellence in intimate bonds. In fact, for Bauman, the modern liquid rationality finds in the commitment a source of oppression, and in a stable rapport the signs of an incapacitating dependence and a trap to avoid (Bauman, 2003). In addition, if we know that our partner can decide to leave us at any moment, in virtue of keeping up a cool relationship, investing feelings into the relationship is definitely a reckless step. Thus, in passing from pre-modern to modern times, the void left by the dissolution of traditional ties and the impossibility of building identities anchored onto the stability of major integrators social frameworks, appears to Bauman to have been "filled up" by a culture of the ephemeral and of affective disengagement that extends the consumer logic to the sphere of intimate relationships, transforming what was previously a question of responsibility and moral obligation to a question of taste, in a process always open to new solutions, contemplating replacements more than adjustments, without any commitment or memory. The social code of connectivity, where connection refers to temporary, superficial, precarious and replaceable interactions, seems to have taken the place of the moral responsibility code as generator mechanism of social ties.

No more commitment without reserve, no more vital importance of love in our life, no more cognition of intimate relationships as a "seeking", an occasion for constructing identities, antidote to loneliness through creating an exclusive rapport with each other, no more romantic love. The feelings of uncertainty on the relationship's future, and the awareness of its fragility, seem to have influenced. The feelings of uncertainty on the relationship's future, and the awareness of its fragility, seem to have influenced the sensitivity by which we project ourselves into the romantic relationship. Now, flexible and easily revocable relations are preferred, lightening the burden of expectations towards partner. And, in so doing, no more suffering when facing the possible breakup of the relationship. Indeed, the specific characteristic of Bauman's reflection is that freedom's ultimate product, today, is a sort of adaptation to uncertainty and to intimate tie fragility generated by the individualization process. For Bauman, the tendency toward mutual sentimental disengagement is no other than the form taken by this adaptation process, and, in a certain way, a resource - the sign of a new post-modern maturity, condensed in the will to embrace the new rules of the game.

The theme of solidarity without shared values which, for Luhmann, characterizes modernity, is exemplified in Bauman's interpretation of today's intimate relationships - relations that appear to form themselves on foundations that do not take into account the shared meaning of love as a value. Love's importance in our lives has encountered a relentless downsizing, a reduction of that essence still vital accorded in Beck's reconstructive framework. On the other hand, as was said above, contrary to Giddens and Beck, for Bauman it is a matter of relationships devised to end without leaving any trace of suffering, identity fractures, 
and/or, reasons for bitter revenge.

Nonetheless, the ease of disengagement and the legitimized interruption of the relationship do not reduce the risks and the anguish of intimate life, for Bauman, but are limited simply to facilitating their redistribution. Uncertainty and ambiguity inherent to the relationships do not disappear but activate a substantially anomic process.

In conclusion, taking stock of the situation, what remains in the present collective consciousness of romantic love's heroines such as Anna Karenina or Emma Bovary? In what way, can they, if they can, still speak to love's actors? Have they lost their allure in the eyes of late modernity interpreters?

For Bauman and Hochscild, the conquest of freedom has produced social effects such as to impact on the way we feel love itself. The fragility of love has ultimately encouraged the awareness that it is not worth investing in feelings, the sensation of an overvaluation of intimacy so that we can only feel love as a game- a game that is not worth taking seriously. As a value, love has been emptied definitively of meaning, impoverished in a remaining superficial, ephemeral and inconsistent love.

However, Giddens and Beck's literature presents a possible different answer.

From the pages of Tolstoy and Flaubert, Anna Karenina and Emma Bovary can still speak to us without fear of being misunderstood. We can still understand their intimate tension toward that You who is able to project them in an ideal dimension of common feelings and intentions against all social conventions, and then feel the same profound disappointment when facing the shattering of ideals against the hard reality of convenience and calculation. Today, this acknowledgment, is a part of our more worldly-wise awareness. However, if on one hand, as Bauman says, it is true that the collapse of institutional constraints and the extreme fragility of human bonds amplify the sensation of uncertainty and this can cause fear and lead to forms of adaptation which place at the center of one's own life the precious good of one's own freedom, the not wanting to be harnessed in the hard and dangerous web of intimate relationships, on the other hand, as Giddens and Beck would lead us to intuit, it is also true that freedom from moral obligations that are aimed at anything other than the truth of love itself and from juridical forever appear to have introduced an element of moralization into relationship. Even in the break up, it celebrates its prerequisites love and freedom—so if it lasts, it lasts freely and romantically for love.

\section{The Volatility of Love. Beyond Structural Coupling Theory: Complexity and Emergence of Couple System}

As we said into the Introduction, Structural Coupling Theory assumes the linearity of mate selection process. Instead, it seems to be better represented by nonlinearity, emergence and unpredictability concepts, thus modulating different implications with reference to intimate partner violence conceptualization.

From a theoretical point of view, this consideration takes account of the statute that contemporary epistemology attributes to linear determinism and to the 
category of predictability in itself by virtue of a change in the system concept as complex adaptive or evolving system.

Today, the category of predictability is the most difficult to sustain from an epistemological point of view, due to profound changes that affected the classical scientific epistemological paradigm in the face of the pressures of Complexity and New General System Theory. Faced with a reality in continuous transformation, Newtonian-Laplacian linear determinism (based on Leibniz principle of sufficient reason-an effect (output) is due to a cause (input) and to the same input there is ever the same and proportional to cause's intensity output (linear and univocal relationships cause-effect: if $\mathrm{A}$ then $\mathrm{B}$, and if $\mathrm{B}$ then $\mathrm{A}$ ) and reductionism (the linked to linearism tendency to treat a system- the whole or macro effect of micro interactions- as mere sum of its parts, as reducible to them) have been questioned, and rejected and the way of conceiving the working and evolution mechanism of systems redefined. The contributions of different, although united by isomorphic epistemological assumptions, disciplines converge in a re-framing of system concept:, for example: principle of order from noise (Von Foerster, 1960), open system concept (Von Bertalanffy, 1968), Law of Requisite Variety and brain studies (Ashby, 1969), formal self-organization theory or principle of organized causaliiy (Atlan, 1974), mathematical communication theory (Shannon \& Weaver, 1948), Dissipative Structure Theory (Prigogine \& Nicolis, 1977; Prigogine \& Stengers, 1979), Synergetics (Haken \& Graham, 1971; Haken, 2004), hypercicles (Eigen \& Schuster, 1977), Autopoiesis Theory (Maturana \& Varela, 1984) and one (Luhmann, 1990), scientists' associated with the Santa Fe Institute work on complex adaptive systems (Langton, 1990; Kauffman, 1995; Gell-Mann, 1994; Miller \& Page, 2007) as well as the work of scientists based in Europe such as Allen (1997) and Goodwin (1994), Axelrod (1984) on cooperation, and on path dependence in Economy (Arthur, 1995). Indeed, self-organization, emergence, novelty, surprise are the words used, today, to describe the new patterns of relationships, the new high-level properties of the system generated by collective dynamics of its components or by nonlinear interactions among its constituent parts (Holland, 1998; McDaniel \& Driebe, 2010).

It is the end of Classic Science, the end of a science able to forecast, which sees systems as stable system, characterized by linear interaction relationships among its components-proportionality constants between input and output, which is guarantee of predictability and controllability of events. It is what Prigogine has defined the End of Certainty (Prigogine, 1997), the end of Positivism and Enlightenment confidence-the Cartesian, Newtonian, Laplacian confidence-in the ability of reason to make the uncertain certain, to reclaim terrains of growing ignorance, to explain, predict and control the future, the unknown (the "savoir pour prévoir", as stated by Auguste Comte).

In the current, in the new epistemological panorama of complexity this trust is gone, by acknowledging the non-linearity and emergence of reality.

Whereas in the framework of the classic paradigm the whole dynamic of evolution tends to stabilize, with no place for surprise, which is absorbed into the 
limbo of randomness, Complexity Science refers to systems as unstable systems, living and transforming in a continuous process, adapting to environmental perturbations by self-organizing, by generating spontaneously (from inner guidelines rather than the imposition of form from the outside) organization and evolving irreversibly towards ever new interaction structures, an ever new, emergent, surprising, unexpected, unpredictable, order, as a result of nonlinearity of interactions and positive feedback among system components ( sensitive dependence on initial conditions). For all systems, natural and social systems, Complexity highlights the emergence and therefore unpredictability of outcomes (at aggregate o macro level) of interaction processes among system components. In this sense, nonlinearity and sensitive dependence on starting conditions are the space of emergence possibilities, of possible alternatives of system self-organization (equifinality of outcomes).

In this framework, self-organization (order for free or supervenience-development of a superordinate structure) nothing else but a process of differentiation as response strategy to environmental perturbations, a new system re-stabilization where differentiation and interdependence among the parts of the system find a balance. In this intermediate position between max order (max connexion) and max disorder ( $\max$ differentiation), far from entropy (equilibrium in a thermodynamic sense) or at the edge of the chaos, Complexity locates the conditions for system's survival, for emergent self-organization and evolution, for production of much richer dynamical properties on global scale than they could be inferred from the properties and behaviours of its individual entities. In this sense, Prigogine does not see degradation in thermodynamic processes and in entropy, but an increase of complexity; in dissipative structures, he sees the place of a combination of order and disorder, and in arrow of time, he sees creation and not dissipation. And, nevertheless, the New Science, by dissolving the association between linearism, determinism and predictability being celebrated in Newtonian and Laplacian universe, makes visible the word as it is, unpredictable and uncertain, though deterministic.

This dialectical synthesis between two categories scientifically and culturally conceived as mutually excluding one another (order-disorder, determinism-probability, being-becoming, necessity-freedom, determination-unpredictability, constraint-possibility, macro (the whole or system, which connects its parts and is condition of their existence) and micro (system's individual components)), being expressed by the concept of deterministic chaos, characterizes the current scientific and cultural revolution, by revising the epistemological meaning of unpredictability and uncertainty, which are now converted into structural elements, that is, into inherent elements to the generator mechanism of real phenomena, even if it is a deterministic mechanism.

This is the novelty of Complexity. Order and disorder, maintenance and change, preservation of system and internal conflict are linked within the same framework. Anti-reductionism implies that uncertainty is no longer, sic et sim- 
pliciter, a condition based on ignorance, nor as a condition depending on chance, in a huge cosmic lottery which assigns to events mere probability of occurrence. Instead, it seems intrinsic to the system. It springs from the law itself that structures the event, from an implicit order which originates inside the system itself. At the edge of chaos, the system continues to be deterministic, constrained by order-generating rules. And, nevertheless it, as a whole, is unpredictable in its dynamic of self-organization and evolution, exhibiting irreducible properties to those of its individual parts because of sensitivity of the system to changes in the starting conditions and nonlinearity. It is the nonlinear interaction of system components to create emergence. Nonlinearity amplifies even small changes in initial conditions of the system, so as to produce disproportionate, unexpected outcomes, escaping the capacity of prediction (butterfly effect). So, at bifurcation points, the choice of one or other branch of the evolutionary process remains unpredictable, considering it is impossible to master, control, and precisely define the system state, that is, its initial conditions and the very small changes in initial conditions to which the system continuously reacts. Even for complex systems consisting of few elements, system evolution, beyond a certain time horizon, remains unpredictable. It results that emergence, surprise, uncertainty, and unpredictability can be regarded as unavoidable conditions, which cannot be eliminated from the most intimate working mechanism of the system. Ignorance can regress, generating laws and mechanisms can be discovered, but all these cannot eliminate unpredictability, which remains inextricably linked to the orderly determinism of occurrences and of their non-linear cause and effect relationships. In this sense, Complexity as emergent self-organization is essential unpredictability (Prigogine, 2010), the property of systems to show possible but not predetermined behaviours, although deterministic. All scenarios become possible, and all that we can predict is just possible scenarios (Condorelli, 2017).

Prigogine has no doubt: surprise and uncertainty are 'essential', inextricably part of human destiny, of nature and of human history (Prigogine, 2010: 16). This is the meaning of the Prigogine's New Alliance: emergence, surprising self-organization, nonlinearity, bifurcations, irreversibility, unpredictability are ubiquitous. They are in physical, psychological, neural, mental, and social systems, constituting a unifying element of our conception of the universe, even beyond its recognized systemic diversity. And this is the meaning of the Morin's "penseè complex" as well. Linear determinism appears to Morin a trivialization of all systems, natural and social systems (Morin, 1977; 2008). The system (the whole) is unitas multiplex, which connects its components in a solidal ring, in a such interweaving of interactions-complementaries, antagonistics, concorrents relationships-that no one exists and can be understand in isolation from the whole, and proceeds by constraints and emergences, by "qualitative jumps".

Social system concept has shifted towards complexity as well.

Nonlinearity, self-organization, emergence, surprise, self-reproduction, operative closure, co-evolution, fitness landscape concepts are entered into sociological 
language, structuring a new way of thinking about social systems as unstable systems, ever-changing systems, able to adapt by autonomy (operational closure) to the disorder produced by loss of stability triggered by environmental perturbations, by self-organizing and evolving into a new interaction structure, new pattern of meanings or social expectations, new emergent, surprising, unexpected, unpredictable order patterns, and new communication through communication (Luhmann, 1986), as a result of nonlinearity of interactions and positive feedback among system inter-agents. Into more specific sociological terms, inputs enter the inter-exchange network of meanings and is processed by inter-agents, being able to activate nonlinear, non proportional to causal inputs, signification processes, and, consequently, equally disproportionate and unpredictable behavioral effects at macro level, beyond the very intentions of the individual inter-agents. Those who interpret social system as complex dynamical systems, such as Morin (1977), Luhmann (1986), Bailey (1994) and Sawyer (2005) did, or such as Byrne (1998), Byrne \& Callaghan (2014) and Reed \& Harvey (1992) suggested, emphasizing the connection between Complex Systems Theory and Sociological Realism, resolve the social emergence issue in the sense of a spontaneous circular bottom-up and up-down process of determination of causal relationships between the parts and the whole, which recognizes the self-reflexivity and rationality of social actors without losing the emergent character of social totality, being expressed by surprising, counter-intuitive, unintended, unexpected and unpredictable patterns of social expectations, which are beyond the intentions of each agent and cannot be explained by reducing them to the properties of individual interactions, considered one by one, in an isolated manner. Micro e macro are re-structured in inter-relational relationships where the macro emerges from non-linear micro local interactions (upward causality) and, in turn, new emergent order connects the parts in a new whole which constrains and re-orients social actions (downward causality process, on the parts), until new perturbation pushes system toward new evolutive trajectories, new self-organization and change process.

The Parsonsian property of equilibrium as tendency toward system stability, self-maintenance of order if disturbed, has been rejected in favour of emergent self-organization process analysis of social systems at the edge of chaos (e.g. assessment of Parson's functionalism, Bailey, 1984). Human organisation is now a non banal-machine ${ }^{11}$, an entity capable of creating ever new order and re-creating itself. On this same track, Luhmann (Luhmann \& De Giorgi, 1992) - who has constructed his theory of modern society on complexity-re-frames the relationship between system and environment by the sociological transposition of concepts of autopoiesis and operational closure (Maturana \& Varela, 1984), which refer to an environment unable to determine but only to suggest self-organization. Even Luhmannian conception of social systems as emergent, self-reproducing, operationally closed communication systems emphasizes the autonomy of social systems compared to environmental perturbation and their "non banality", disputing the idea of change processes as mere, linear, reaction to external causes (linear 
cause-effect or input/output processes) in favor of emergence, The convergence and stabilization of meaning in social interactions, which is indispensable to form a social system and which is made difficult because of double contingency, emerges spontaneously by selection among many possible meanings. In the face of complexity as multiplicity of possibilities and selection among them, social system emerges and serves to reduce complexity (up-down). Produced Laws, money, power, love allows social actors to reduce complexity, the possibilities of emergence, uncertainty/unpredictability of outcomes of interaction and selection processes in different contexts of social interactions. Nevertheless, the capacity of social systems to produce by itself its own elements, by reproducing communications through communications, is rooted on the theoretical assumption of a system that, responding to environmental disturbance entering into the autopoietic communication network, decides whether and how to react, whether and how to change, according to its structure, without losing its own identity, by autono$m y$ with respect to environment perturbations (operational closure), redefining by differentiation its boundaries with respect to the environment, and reducing, in so doing, complexity. At the same time, it reproduces complexity, due to the same functional and symbolic differentiation which increases the variety of factors which should be taken in consideration in decision making interaction processes. Information decreases while decision uncertainty increases, increasing the possibilities of emergence, of difficult to predict new social structures, new self-organizing outcomes.

Decision making and problem solving processes outcome (a behavioural decision) emerges via an iterative dynamical process. Decision outcomes can be discontinuous, shifting between different behavioural modes (self-organization or attractor state), as a result of a nonlinear dynamical process. Therefore, in these decision processes unpredictable behaviors are expected. Obviously, decision-making process can be emergent "if and only if the system is set to function freely under certain constraints, but not in a predetermined scenario under imposed choices, as in this case it would be a linear process" (Stamovlasis \&

${ }^{11} \mathrm{~A}$ machine is banal if at the same input ever there is the same output, due to a linear and univocal relationship between cause and effect. In a non-banal machine the output which it produces depends not just on input, but also on internal state of machine itself. From the Autopoiesis Theory perspective, the system's structure has, therefore, within itself the rules of its own transformation. At the same input or perturbation there can be different outputs (or system behaviors), according to the internal state of the machine (i.e. the structure it had before being disrupted). There are some differences in terminology between the Autopoiesis Theory, and all approaches which on the whole constitute Complexity Theory, such as the Theory of Adaptive Systems and Dissipative Structure Theory. What these latter call organization, or the pattern of interactions among the elements or components constituting the system, is called structure. Instead, organization is considered the set of relationships among the elements that define the system's identity-its essential characteristics which cannot be lacking. The organization may take on different types of structures, different patterns of interaction that the system can take over without, however, losing its identity or organization. The structure is the physical materialization of the organization, the set of components and interactions that it tangibly produces. From this perspective, ontogenesis is the process of the system's structural change (equivalent to what is called process of self-organization in the other two theories) that takes place without the loss of system identity or organization. 
Vaioupoulou, 2017: 281; Nicolis, 1991). In this sense, in the Luhmannian sociology, modern individualistic society, in particular, possess all conditions in order a system is a complex system. Not only the decision is now analytically understood as emergent itself, but, in a context which self-organizes by producing emergence, as a process which loses the control over its own products.

In synthesis, all classic issues of Sociology (Parsonsian social system concept, social emergence, social change and predictability concepts, the relationship between micro-macro levels of analysis, between system and environment, order and disorder) have been re-specifyed from an anti-reductionist/emergentist perspective synthesizing in the complex realism concept the tension between sociological critical realism and post-modern vitalism, between search for general theory and instances of contextual understandings (Harvey \& Reed, 1997). The emergent self-organization construct allows Byrne (1998), Byrne \& Callaghan (2014) to underscore the compatibility between sociological realism (the idea of a stable order of sense in line with the conception of a deterministic world, with an intrinsic order) and complexity theory (nonlinear determinism or emergence). While Cilliers (1998) argues complexity's compatibility with postmodernism (by emphasizing the lack of stable sources of sense and rational teleology of history, the dismissal of the possibility of social causality and systematic social inquiry in favour of the uncertainty, unpredictability and surprise), theoretical position of complex realism grasps the potential of Complexity Theory of going beyond dichotomy between post-modernism and realism, linking determinism and unpredictability, order and disorder (Reed \& Harvey, 1992). It remains within the modernist programme of progressive thought, and rejects at the same time the canons of reductionist positivism and postmodernism.

Emphasis on emergent self-organization and surprise has re-addressed the way of thinking about the aim of Social Sciences as well: we must attempt to understand underlying mechanisms governing social phenomena by modelling nonlinear social interactions, but we should resize our claims of predictability and control. As well as in Physical Sciences, social system's sensitivity to change of initial conditions and emergence challenge such claims and pushes to a necessary caution. For example, electoral competition processes reveal very volatile and unpredictable processes (Brown, 1991; McBarnett, 1996). The winner could say everything except the inevitability of his victory, being dependent on initial conditions on which (and on whose, even small, change) our control is absolutely null, and, therefore, being unknowable and unknown. We can only imagine scenarios, although must explain the processes of electoral competition, identify the factors involved in structuring the processes of interaction in decision-making systems aimed at voting. No wonder that electoral volatility is one of the most profitable field of study for the application of nonlinear models, along with phenomena such as arms race, spread of innovations and deviant behaviors, urban development, social control processes, education and health dynamics, organization management, human resource management, international political relations, economics, marketing and business processes, suicidal behaviors in Sociology and Psychology (for sociologi- 
cal bibliography see Condorelli, 2016; see also Schiepek et al., 2011; Mitleton-Kelly, 2003; Truss \& Gill, 2004; Allen et al. 2011).

But, then, how can we say differently about the partner's choice process? How can each one which is involved in a decision-making process aiming at choosing a sentimental partner to be sure be chosen? Here, the same rule that applies to electoral volatility seems to be valid: much more realistically, every potential partner can say everything except the inevitability of his own success, depending on unknown and unknowable initial conditions.

In this sense, by applying the modern language of Complexity couple can be understood as the surprising, emergent result of a micro interaction system between inter-agents involving in a mate selection decision-making process. The variety of factors which modernity, with its differentiation processes which have harnessed traditional constraints, enables to come into play in decision-making interaction system amplifies the condition of system's sensitive dependence on changes, even small, in starting conditions and, therefore, amplifies the possibilities of emergence. So, partner's choice, and the couple as emergent self-organization of interaction system, is neither determinable nor predictable. Nothing certain can be said on the outcome of mate selection process (whether or not partner will be chosen, who will be chosen...). Uncertainty reigns sovereign. Every possibility is now open, every scenario possible, and no one knows what will arise. Partner's choice remains an surprising process: for partners itself and for a science of intimate relationships, which can explain, know the factors which impact on interaction and partner selection process, but not predict the outcome of the process itself.

The same logic and conceptual categories of complex systems can be applied to couple system once formed, referring to relationship's evolution. In Simmel's conceptualization of modern couple (posthumous publication, Simmel, 1921), and again in recent ones, such as Beck, partners interact, creating a new and unique whole, an individualized unity with properties that differentiate each system from any other. This common conception of the couple as the macro result of micro interactions finds an objective correspondence just in today's structuration of social systems deriving from the modern General System Theory. In celebrating the Complexity Theory the discontinuity, instability and unpredictability of systems in their work and evolution mechanism, the couple-system shows all its complexity. The modern couple's possibility to adapt to external disturbances by spontaneously, autonomously, self-organizing into ever new forms, alone deciding the destiny of the relationship itself, without any further externally imposed rules, is associated with the emergence and unpredictability of its self organization process, up to contemplating the possibility of a break up when every possible connection, even the smallest, between the two parties is cut off.. By correlating emergence to autonomy and identity characterizations of the system itself, the concept of operative closure, elaborated by Maturana and Varela and used by Luhmann to represent social systems as au- 
topoietic, emergent communication systems, is qualified to represent the couple-system, which behaves like a non-banal machine: it autonomously responds to possible disturbances to its order, depending on its specific internal characterization, on the peculiarity of the partner relationships, and on the expectations and situated meanings that, from time to time, are exchanged and constructed. Every possibility is now open, every scenario possible: happiness, stability, boredom, destruction, to use Beck's own word. Couple stability as well as its degree of conflict is surprising, emerging, unpredictable properties of couple system, which are not reducible to the individual properties of single agents. Macro emerges from micro, but it is "greater than the sum of single parts": it is an effect of the system, of interaction on the whole. At the same time, the emergent quality of the relationship constrains partners so that individual qualities of each one are inexpressible outside of their relationship itself.

It is evident that the partner's choice concept as emergent systemic self-organization diverges from Structural Coupling Theory assumptions, producing different implications.

As we previously said, to say that everything is possible, that any choice is possible, is to say that any structural coupling is possible, although we can remain in a deterministic framework. And, referring to intimate partner violence issue, this means a change of perspective than structural coupling hypothesis: if any structural coupling is possible, this means we should think of this experience as an event that can happen not only to one type of woman but to all women, anywoman (secure, avoidant, or ambivalent).

This long discussion is the premise of the following research.

\section{The Present Study}

Although without advancing any inferential claims (for obvious reasons, the subject matter does not lend itself to favor the building of a representative, random, sample of gender-based violence victims), we attempt to test the psycho-behavioral hypothesis of structural coupling, assuming an avoidant attachment style for victims. We assume the hypothesis that victimization risk can be distributed to all women, in line with the idea that partner's choice is the surprising, emergent result (or self-organization) of interaction between individuals which behave as a complex system, able to exhibit a sensitive dependence on perturbations, even small, of system's initial conditions which makes unpredictable and undeterminable partner selection process. As previously said, if the first hypothesis is valid, we expect that the sample's victims are women with avoidant attachment style. Otherwise, we expect a wide heterogeneity of attachment styles. By considering current sociological interpretations of post-modern intimate life, we assume that cultural expectations about intimacy can be one of factors able to orient partner choice, amplifying the system's sensitivity condition and possibilities of emergence. Consequently, we attempt to test their role in partner selection processes in our sample. 


\subsection{Method}

\subsubsection{Participants}

The study was conducted on a sample of 100 women affected by intimate partner violence, who were recruited in collaboration with several Antiviolence Centers throughout Sicily (i.e., Catania, Messina, Syracuse). The sample consisted of women who were victimized mainly from their husband (10\% from cohabiting partner), aged between 22 and 61 years (most represented age group: 40 - 49 years old). Regarding education, about 87 victims (87\%) had high education (51\% diploma, university (36\%), Master (7\%)). $45 \%$ of victims was housewife (mostly women which had been forced from partner to leave their employment), and 55\% was employed women (public or private employees). All participants were separated or divorced after a long relationship (e.g. from 11 to 20 years for $34 \%$ of victims, 20 years and over for $26 \%$ ).

\subsubsection{Instruments}

A questionnaire was administered which included some open-ended question subgroups.

The first subgroup included items relating to socio-demographic characteristics (i.e. sex, age, education, marital status, professional roles) and to couple's life: length of the relationship, time between engagement and marriage (or stabilization of relationship), time between the beginning of the relationship and first episodes of violence, victim's expectations about the relationship at its beginning. The interviewees provided some model descriptions of couple life in order to reconstruct crucial phases of the violent relationship, types of injuries women sustained and partner's characteristics at the beginning of the relationship and subsequent changes.

The second subgroup included items addressing mate preference issue. Main criteria which were used to select partner (Mate Preferences Questionnaire) were asked, and the incidence of romantic love complex cultural model was tested.

The Psycho-behavioral hypothesis was tested by using the AAQ (Adult Attachment Questionnaire or Attachment Style Measure), the classic survey instrument developed by Hazan \& Shaver (1987) to detect adult attachment styles. As already said, this is the most enduring contribution of Hazan and Shaver's work. They created short paragraph that described the adult analogues of the Strange Situation types (see note 6) and asked adult participants to indicate which of three description best captured their thoughts, feelings, and behaviours in close relationships (Table 1). As far as other scales have been developed, they are based on the descriptions of Hazan and Shaver's three attachment styles. In this regard, Collins and Reed maintained that "the concept of discrete attachment styles", cannot be abandoned "because it is important both conceptually and theoretically" (Collins \& Reed, 1990: 661).

Secondly, the analysis used Faces III (Family Adaptation and Cohesion Evaluation Scale) as a control instrument supporting the $A A Q$ (Table 2). This 
Table 1. Attachment style measure and sample distribution.

\begin{tabular}{|c|c|}
\hline Question: Which of the following best describes your feelings? & Sample: $\mathrm{N}=100$ \\
\hline $\begin{array}{l}\text { 1) Secure - I find it relatively easy to get close to others and am } \\
\text { comfortable depending on them and having them depend on me. } \\
\text { I don't often worry about being abandoned or about someone } \\
\text { get-ting too close to me. }\end{array}$ & $60(60 \%)$ \\
\hline $\begin{array}{l}\text { 2) Avoidant Insecure-I am somewhat uncomfortable being } \\
\text { close to others; I find it difficult to trust them, difficult to allow } \\
\text { myself to depend on them. I am nervous when anyone gets too } \\
\text { close, and often, love partners want me to be more intimate than } \\
\text { I feel comfort-table being. }\end{array}$ & $28(28 \%)$ \\
\hline $\begin{array}{l}\text { 3) Anxious/Ambivalent Insecure-I find that others are reluc- } \\
\text { tant to get as close as I would like. I often worry that my partner } \\
\text { doesn't really love me or won't want to stay with me. I want to } \\
\text { merge completely with another person, and this desire sometimes } \\
\text { scares people away. }\end{array}$ & $12(12 \%)$ \\
\hline
\end{tabular}

Table 2. Faces III (Family Adaptation and Cohesion Scales).

\begin{tabular}{ccccc}
\hline Almost never & Once in a while & Sometimes & Frequently & Almost always \\
\hline 1 & 2 & 3 & 4 & 5 \\
\hline \multicolumn{4}{c}{ Describe your family now (original family) }
\end{tabular}

1) Family members ask each other for help

2) In solving problem, the children's suggestion are followed

3) We approve of each other's friends

4) Children have a say in their decision

5) We like to do things with just our immediate family

6) Different persons act as leaders in our family

7) Family members feel closer to others family members than to people outside the family

8) Our family changes its way of handling tasks

9) Family members like to spend free time with each other

10) Parent(s) and children discuss punishment together

11) Family members feel very close to each other

12) The children make the decisions in our family

13) When our family gets together for activities, everybody is present

14) Rules change in our family

15) We can easily think of things to do together as a family

16) We shift household responsibilities from person to person

17) Family members consult other family members on their decision

18) It is hard to identify the leader(s) in our family

19) Family togetherness is very important

20) It is hard to tell who does which household chores 
instrument is a self-report questionnaire that was elaborated by Olson (Olson et al., 1985; see also Olson, 1986; Green et al., 1991) to find and measure modalities of relationship (level of Cohesion) and functioning (Level of Flexibility or Adaptability to environmental stress) of the family, according to each family member's perceptions of these dimensions. Faces III was used to give an account of the attachment styles found, being confident that the data was not affected by the quality of couples' on-going relationships. Indeed, from a theoretical point of view, this use is justified by integration of Bowlby's dyadic relational theory with the analysis of dynamics of the whole family system which, in the recent years, the systemic-relational behavioral psychology has theorized, assuming a direct correlation between individual attachment styles and level of Cohesion and Flexibilityl Adaptability of relationships within the family of origin (Loriedo \& Picardi, 2000). The Cohesion dimension refers to the intensity of affective/emotional ties that unite family members-degree at which family member are separated from or connected to their family-and to the autonomy of the individual within the family. Whereas, Flexibility indicates the homeostatic or adapting capacity (in the meaning of the relationship between morphostasis and morphogenesis, stability and change process) of the family system to environmental stresses-degree at which the family system is flexible and able to change, through possible changes in internal rules, distribution of roles and leadership. Faces III can be used to survey the perception that interviewees have of their family of origin as well as current family A secure attachment style implies balanced levels of Cohesion and Flexibility of original family Insecure attachment styles imply dysfunctional families of origin.

In more details, Faces IIII (Italian adaptation by Galimberti \& Farina, 1990) consists of a 5 point Lickert scale, ranging from $1=$ almost never to score $5=$ almost always, comprising 20 items: 10 measure family Cohesion, with 2 items per 5 representative area: emotional tie, mutual support, cooperation, family boundaries, interests and common friendships (for example: Family members ask each other for help; Family members feel very close to each other, Family togetherness is very important). The other 10 items measure Flexibility/Adaptability, with 2 items each per area of control, power and discipline, and 4 dealing with the area of roles and rules, (for example: Children have a say in their decision; Our family changes its way of handling tasks; Rules change in our family) For each item or statement the respondents is asked to decide how frequently, on a scale that range from 1 (almost never) to 5 (almost always), the described behavior occurs in his/her family. The items are presented in alternating sequence order, so that the score relating to Cohesion is obtained by adding the 10 odd-numbered items, while the score relating to Adaptability is the result of adding the 10 even-numbered items. Ranks or cutting points define 4 scoring ranges or levels of Cohesion and 4 levels of Adaptability. There are four levels of family cohesion ranging from extreme low cohesion to extreme high cohesion: disengaged, separated, connected, and enmeshed. There are four levels of adaptability: rigid, structured, flexible, chaotic. In particular, following Ardone \& D’Atena (1988), for every Cohesion level we obtain re- 
spectively: disengaged families (score from 10 to 31: very low cohesion level, i.e. scarce emotional ties among family members); separated (score of 32 - 37: between low and moderate cohesion levels); connected (score of 38 to 43: between moderate and high cohesion levels ) and enmeshed (43 to 50: very high cohesion, i.e. very intense ties, lack of personal autonomy for each family component). The levels of Cohesion found at the center of the scale, i.e. separated and connected families, represent optimal family Cohesion, whereas, levels at both extremes (disengagement and enmeshment) are considered dysfunctional, with problematic implications for family members. As far as Flexibility/Adaptability is concerned, the cut off scores distinguish 4 functioning levels: rigid families (score of 10 - 25: very low Adaptability, with authoritarian leadership, sharing rigid roles, low propensity for change); structured family (score of 25 - 30: between low and moderate levels of Adaptability); flexible (score of 31 - 35: between moderate and high Adaptability levels); chaotic (score of 36 - 50: very high level of Adaptability, with interminable negotiations and undefined leadership). Also in this case, the virtuous level of Adaptability is expressed by structured and flexible families, whereas the extreme rigid and chaotic ones represent functional problematic levels of Adaptability.

Combinations of the scoring ranges characterizing each dimension, allow Olson to represent 16 types of family functioning. This is the Circumplex Model (Figure 1), a classification system of 16 family types and three more general types (balanced, mid-range, and extreme families), which includes functional and dysfunctional families. Balanced families (found at the model's center), with optimal functioning, are the flexibly separated, flexibly connected, structurally separated, and structurally connected. Extreme families (at the edges of the model), with dysfunctional functioning, are rigidly enmeshed, rigidly disengaged, chaotically enmeshed, and chaotically disengaged. The remaining combinations define the Mid Range families, balanced on only one of the two dimensions.

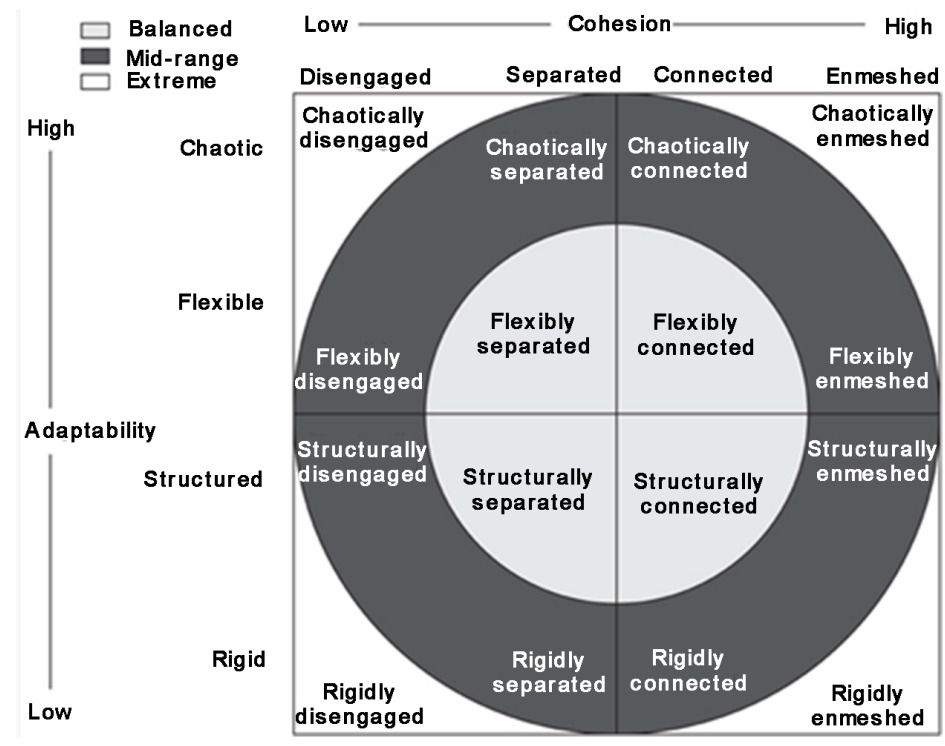

Figure 1. Circumplex model source: Olson et al. (1985). 
Faces III has fairly high internal consistency $(r=0.68)$ as well as high test-retest reliability $(r=0.80)$, and for validity, there is very low correlation between scales $(r=0.03)$. The theory of curvilinearity-the idea that the model's two key dimensions of cohesion and adaptability form a curvilinear rather than linear relationship with effective family functioning-is rejected (e.g. Cluff et al., 1994). The instrument can be used to survey the perception that interviewees have of their family of origin, their current family and even their ideal family. The discrepancy between present family functioning and ideal functioning provides an inverse measure of family satisfaction: a high discrepancy indicates a high level of dissatisfaction; a low discrepancy indicates a low level of dissatisfaction (Mazzoni \& Tafà, 2007).

As I previously said, the optimal family functioning model, i.e. the one located in an area which Olson defined as the Balanced area, would account for a secure attachment style as it is constituted by separated/structured and connected/flexible relations, able in both cases to promote a good level of cohesion/connection among family members while respecting each other's freedom and differentiation, on the one hand, and, on the other hand, a good level of adaptation to environmental stresses in order to preserve family stability. Family models unable to maintain this balance and, consequently, dysfunctional, being of the disengaged/rigid typology (low levels of Cohesion and Flexibility) or enmeshed/chaotic type (excessively high levels of Cohesion and Flexibility), would account for an insecure (avoidant or ambivalent) attachment style.

By administration of Faces III, the interviewees asked to describe their family of origin and were placed in one of the 16 family types of the Circumplex model, depending on individual scores on each dimension and their combination. Attachment style distribution on Circumplex model was analyzed, and the correlation between Attachment style and Cohesion/Flexibility level of original family system was calculated (Kendall's Tau $c$ association test). Since our sample was not random, inferential statistics techniques were not applied. The findings can be regarded as suggesting in a study based on a larger representative sample.

Faces III seemed the most suitable instrument for the requirements of this study, although, after a long and valid use, Olson replaced it with a newer version (Olson et al., 2004). Faces $I V$ does not distort the previous version but makes its articulation and administration more complex, with six scales to directly identify balanced and unbalanced aspects of Cohesion and Flexibility, one scale for Communication and one for Family Satisfaction (for Italian adaptation see Visani et al., 2014).

\subsubsection{Statistical Analysis}

Data were processed by SPSS 20.0.

\section{Results}

Sample's socio-demographic features join the present research to other studies which detached the victimization from the idea that it can be significantly related to lower classes and less educated people (e.g. Mullen, Pathé, \& Purcell, 
2009). Heterogeneous in age, education, and social class, the sample, although not representative, it does not confirm certain traditional clichés. It seems that high education levels and subsequent social conditions do not serve to protect a woman from becoming a victim ( $87 \%$ of victims -87 on the sample of 100 victims-had medium-high education level) as well as they do not serve to prevent that man becomes a potential violent partner ( $80 \%$ of abusive partners had medium-high level of education). Intimate partner violence nests in all education levels and social class, and with common, transversal, traits. All victims describe a partner which, independent on education level and social class, seems to present the typical features of an ambivalent, in need of affection, but insecure, anxious and, for this reason, controlling, oppressive in an effort to reduce the uncertainty of relationship and the fear of being abandoned (typical fear of an ambivalent). On the part of the abusers, there are all strategies able to mutilate the abused victim's identity, to deprive her of her own will, so as to make her, by applying a Goffmanian interpretation, malleable, easily controllable, in a severe escalation of violence characterized by multiple forms of emotional-psychological, sexual and physical abuses and controlling behaviours (the so called battering): isolation ( $86 \%$ of victims was forced to drastically reduce their own relationships with original family and friends, 39\% was forced to leave their employment), deprivation of legitimate acts of free individual volition by an increasing monitoring victim's movements (including call phones) and restrictions to access to financial resources; continuous denigrations and disapprovals (verbal abuses such as insults, belittling, constant humiliations-as a mother, wife and person), terrorization by intimidations (e.g. destroying of things, threats of physical harm, threats to take away children), forced sexual intercourses, simple and aggravated physical assaults (slapping, beating up to-for 20 victims-attempted murder).

Nevertheless, on the part of the victims, we are not facing partner's choices that were hasty and little thought out. Intimate partner violent behavior was sudden and unexpected, for the most part initiating after the relationship formalization or stabilization. Before, there were signs of jealousy and possessiveness. But they were interpreted by the victims as normal signs of falling in love. The schema is that of prey-predator relationship. More important was that, at the start of the relationship, before marriage or cohabitation, the partner, according to the surveyed ( $97 \%$ out of 100 valid responses), embodied the ideal man: an other in whom they acknowledged and completed themselves, able to give a dedicated love, reliable, respectful, sharing the same expectations of a lasting stable relationship, with the same values centered around family. Mostly, the first abusiveness episode occurred within the first six months of marriage or cohabitation (82\%) and after a long pre-marital period (about 5 years in $70 \%$ of cases and even from 6 to 11 years in 21\%). This can confirm in the direction of partner's ambivalence hypothesis: the enclosure of matrimonial bond is the "safest" place where partner's insecurity can be turned into an anomic, increasingly possessive, obsessive and controlling behaviour.

As well as victim's personality structure is concerned as predictor of partner's 
choice and victimization risk, after having administered the Attachment Style Measure, we did not find the signs of a linear inverse relationship between degree of security and victimization risk, as Structural Coupling Hypothesis expects (namely, an avoidant personality structure for the victims). Rather a heterogeneous array of attachment styles was found: only $28 \%$ of the victims ( 28 surveyed) were classified as avoidant, $12 \%$ (12) as anxious/ambivalent, whereas $60 \%$ (60) as secure (Table 1). Moreover, the use of Faces III (Family Adaptation and Cohesion Evaluation Scale), as a control instrument supporting the $A A Q$, showed that these results was fairly reliable. The reasons of this use and model description were exposed in the Method section. Here, we merely point out that the optimal family's functioning model, i.e. the one located in an area which Olson defined as the Balanced area, would account for a secure attachment style as it is constituted by separated/structured and connected/flexible relations, able in both cases to promote a good level of cohesion/connection among family members while respecting each other's freedom and differentiation as well as a good level of adaptation to environmental stresses in order to preserve family stability. Family models unable to maintain this balance and, consequently, dysfunctional, being of the disengaged/rigid (low levels of Cohesion and Flexibility) or enmeshedl chaotic type (excessively high levels of Cohesion and Flexibility), would account for an insecure (avoidant or ambivalent) attachment style.

After administering the Faces III to the sample, calculating individual scores on Cohesion and Flexibility dimensions, and considering the Attachment Style distribution on the family types corresponding at different scoring ranges, results confirmed our predictions. By the combination of different scoring ranges, secure and insecure victims were placed in one of the 16 family types of the Circumplex model. Table 3 shows that the sample was quite polarized. Synthetic Table 4 points out that for $55 \%$ of insecure victims (22 among ambivalent and avoidant interviewees out of 40) a rigidl disengaged (very low Cohesion level and very low Adaptability level; scoring combination in the range, respectively, 10 31 and 10 - 25) and separated/rigid family type (between low and moderate

Table 3. Attachment style distribution into circumplex model.

\begin{tabular}{cccc}
\hline Disengaged/rigid & Disengaged/structured & Disengaged/flexible & Disengaged/chaotic \\
Ambivalent $=5$ & Ambivalent $=0$ & Ambivalent $=0$ & Ambivalent $=0$ \\
Avoidant $=12$ & Avoidant $=0$ & Avoidant $=0$ & Avoidant $=0$ \\
Secure $=8$ & Secure $=0$ & Secure $=0$ & Secure $=0$ \\
Separated/rigid & Separated/structured & Separated $/$ flexible & Separated $/$ chaotic \\
Ambivalent $=4$ & Ambivalent $=3$ & Ambivalent $=0$ & Ambivalent $=0$ \\
Avoidant $=1$ & Avoidant $=15$ & Avoidant $=0$ & Avoidant $=0$ \\
Secure $=0$ & Secure $=52$ & Secure $=0$ & Secure $=0$ \\
Connected/rigid & Connected $/$ structured & Connected $/$ flexible & Connected $/$ chaotic \\
Ambivalent $=0$ & Ambivalent $=0$ & Ambivalent $=0$ & Ambivalent $=0$ \\
Avoidant $=0$ & Avoidant $=0$ & Avoidant $=0$ & Avoidant $=0$ \\
Secure $=0$ & Secure $=0$ & Secure $=0$ & Secure $=0$ \\
Enmeshed $/$ rigid & Enmeshed $/$ structured & Enmeshed $/$ flexible & Enmeshed $/$ chaotic \\
Ambivalent $=0$ & Ambivalent $=0$ & Ambivalent $=0$ & Ambivalent $=0$ \\
Avoidant $=0$ & Avoidant $=0$ & Avoidant $=0$ & Avoidant $=0$ \\
Secure $=0$ & Secure $=0$ & Secure $=0$ & Secure $=0$
\end{tabular}


Table 4. Analysis of Relationship between Attachment Style and Family Types-Kendall's Tau c coefficient of association.

\begin{tabular}{ccccc}
\hline & $\begin{array}{c}\text { Disengaged/Rigid }+ \\
\text { Separated/Rigid \% }\end{array}$ & $\begin{array}{c}\text { Separated } \\
\text { Structured } \%\end{array}$ & Statistics \\
\hline AAS & & & & \\
$\begin{array}{c}\text { Avoidant }+ \text { Ambivalent } \\
\text { Insecure }\end{array}$ & $22(55.0)$ & $18(45.0)$ & 40 & \\
Secure & $8(13.0)$ & $52(87.0)$ & 60 & $\tau_{c}=0.40$ \\
Tot. & 30 & 70 & 100 & \\
\hline
\end{tabular}

Cohesion levels and very low Adaptability; scoring combination in the range, respectively, 32 - 37 and 10 - 25) was reported vs 13\% of secure victims (8 interviewees out of 60 ). Whereas, $87 \%$ of the secure surveyed (52 interviewees out of 60) showed a separatedlstructured family type (Balanced Cohesion and Flexibility: between low and moderate Cohesion and Adaptability levels; scoring combination in the range, respectively, $32-37$ and 25 - 30) vs $45 \%$ of insecure victims (18 interviewees out of 40). A Kendall Tau c value of 0.40 confirmed a good association between security degree of attachment style and level of Cohesion/Flexibility of family of origin, allowing us to trust the reliability of the data obtained regarding attachment styles and their distribution among the sample (since inferential reasoning was not carried out, as indicated above, the significance of the coefficient was not reported. The same applies for all subsequent $\tau_{c}$ association coefficients between variables we calculated).

Findings do not exclude that victims' personality structure can affect mate selection process, but it is not a sufficient predictor of partner's choice and victimization risk. Taken into account that, as previously said, a preoccupied or ambivalent personality for abusive partner is a fact already acquired by numerous research evidences, findings lead to concluding that all structural coupling are possible. On the part of victim's, partner's choice seems open to all possibilities of interaction outcomes. Does partner choice sensitive to other factors being likely to come into play in interaction process? Is love the last anchoring to the fragility of modern identity? In this sense, or, as Bauman says, modernity, by transforming love in a free choice matter and by female emancipation, has frayed relationship and, in so doing, has deconstructed expectations, has reduced them to a minimum and made essentially without an internal order the choice process. Or, as Beck says, placing the fate of relationships into partners' own hands, without externally imposed rules, without strong feelings of moral obligation unless they are geared towards their own happiness, is associated with a disposition to the relationship that feeds yet of romantic aspirations, the first of which is the ideal of "couple" as the completion of an imperfect singularity in a unique and unrepeatable way. This is the conception that Simmel restores to us when he outlines the characteristics of love that modernity has rendered possible. It is the idea of a common biographical with "another" in whom we can recognize and complete oneself that Giddens described as the characteristic of romantic love. And it is the "fundamentalist" faith in that 
"at least You" in which even today Beck sees the victory of romanticism. Romantic love would still not lose its symbolic impact on the way of conceiving the choices in intimate life. Transcendence, exaltation without compromises, stable commitment, search of "myself in you", expectation of a happiness founded upon the sharing of intents, mutual emotional and sexual trust, desire for a lasting union, would continue to survive as ideals, despite the fact that, in the meantime, the love testing ground has changed, being no longer played within prescribed institutional constraints but, for the same logic of free choice in intimate, only within free negotiation. Romantic expectations would persist and constitute one of many possible factors of choice, which contributes, in the complexity perspective, to amplify the possibilities of emergence.

This being stated, the interviewees were asked to graduate the following expectations to be met in partner's choice: relationship stability, a You in which one can mirror and complete oneself, mutual trust, sharing of innermost feelings, thoughts, intents and strong values like the family, mutual respect and understanding, protection and care, physical attraction and financial success (Table 5). For $95 \%$ of the surveyed women (95 out of $\mathrm{N}=100$ ), the romantic aspiration toward a union based on a stable bond was the primary expectation. In line with this finding, the importance of a You in which one can mirror and complete oneself, able to give a true and responsible love, being made up of sharing of innermost feelings, thoughts, intents and values (family value), and the trust, were the most frequently sought out qualities in partners (for each dimension, $81 \%$, $68 \%, 68 \%$ of valid answers out of the 100 surveyed). Next came the ability to create an intimate union in mutual respecting of individual identity and mutual understanding (respectively, 66\%, 65\% out of 100). Meeting these criteria was recognized to be more important than other criteria such as physical attraction (30\%) and partner's financial success (12\%). However necessary these were deemed, neither of these two criteria was considered a sufficient element of evaluation and choice for creating a solid family bond. Finally, only 36 out of

Table 5. Expectations in mate selection process by rank.

\begin{tabular}{lc}
\hline \multicolumn{1}{c}{ In partner choice, following expectations should be meet: } & TOT N $=100 \%$ \\
\hline 1) Stable Relationship & $95(95.0)$ \\
2) You in which one can mirror and complete oneself & $81(81.0)$ \\
3) Sharing of innermost feelings, thoughts, intents, and values & $68(68.0)$ \\
(like the family) & $68(68.0)$ \\
4) Trust & $66(66.0)$ \\
5) Respecting of individual identity & $65(65.0)$ \\
6) Mutual understanding & $36(36.0)$ \\
7) Protection and care & $30(30.0)$ \\
8) Physical attraction & $12(12.0)$ \\
9) Financial success & \\
\hline
\end{tabular}


100 respondents $(36 \%)$ were sensitive to the dimension regarding the partner's capacity to offer protection and care. Perhaps, this dimension conveyed the idea of possessiveness and control or the belittling idea of the inability of being autonomous.

On the whole, more than $80 \%$ of 60 victims with secure attachment style have shown this orientation. Nevertheless, even insecure women were not indifferent to it. For example, Table 6 shows there was no substantial difference between victims with secure attachment style $(\mathrm{N}=60)$ and victims with insecure-avoidant attachment style $(\mathrm{N}=28)$. No difference was found regarding the importance to be assigned to expectation of an stable relationship (98\% - 59\% surveyed with secure attachment style out of 60 vs $93 \%$ - 26\% surveyed out of $28, \tau_{c}=0.04$ ), and to search for a partner able to confirm and complete one's own identity: $80 \%$ of secure attachment style victims (48 surveyed out of 60 valid surveys) vs $75.0 \%$ (21 surveyed out of 28) of insecure-avoidant victims agreed in giving primary importance to this dimension in couple's selection process. A low 0.04 value of Kendall's Tau $c$ coefficient ${ }^{12}$ attests to the lack of relationship between the two variables. Similar conclusions were gathered from attachment style distribution on the other dimensions considered. The differences found did not appear such as to signify a decisive and discriminating impact of attachment style on partner choice orientation criteria. This applies in reference to the sharing of intents and values dimension (family and loyalty/fidelity) (66.7\% - 40\% surveyed with secure attachment style out of 60 vs $57.1 \%$ - $16 \%$ surveyed out of $\left.28, \tau_{c}=0.083\right)$, mutual respect $(71.7 \%$ (43) vs 64.0\% (18), $\left.\tau_{c}=0.06\right)$ and understanding (66\% (40) vs 56.4\% (16), $\tau_{c}=$ 0.083). A weak correlation on trust expectation seemed to confirm to some extent the skepticism of the avoidant in trusting others (70\% (42 out of 60 secure victims) vs $54 \%$ ( 15 out 28 avoidant insecure victims), $\tau_{c}=0.143$ ).

In conclusion, a value orientation in which the traditional romantic aspiration toward a stable love is combined with the more modern idea of a communion of equals seems to transversally pass the attachment styles in nourishing couple's expectations. And there is another interesting aspect. Literature on partner's choice would have shown that ideals may serve three basic functions, namely evaluation, explanation, and regulation of current romantic relationships, and that consistency between ideal standards and current romantic partner characteristics may function in initiating and maintaining relationships (e.g. Fletcher et al., 2000). In this sense, as previously said, it may be interesting that, according to the surveyed ( $97 \%$ out of 88 valid responses), at the start of the relationship partner appeared the sought ideal man, the soul mate: an other in whom they could complete themselves, able to give a reliable love and share emotions, thoughts and values.

${ }^{12}$ Kendall's Tau c coefficient, whose formula is $\tau_{c}=4(\mathrm{ad}-\mathrm{bc}) / \mathrm{N} 2$, is a more reliable test than $\phi$ coefficient for measurement of relationship between two dichotomous variables with balanced as well as unbalanced frequencies. Indeed, it has been shown that the more unbalanced the frequencies of a diagonal in $2 \times 2$ table are (therefore, the lower is the variance of each dichotomy), the less reliable the phi values are, overestimating the existence of a relationship among variables which instead is not there or is weak. If the frequencies are balanced $\tau_{c}=\phi$. 
Table 6. Analysis of Relationship between Attachment Style and Expectation Structure in Mate Selection Process-Kendall's Tau c coefficient of association.

\begin{tabular}{|c|c|c|c|c|}
\hline $\begin{array}{l}\text { In partner choice, following } \\
\text { expectations should be meet: }\end{array}$ & Agree $\%$ of $N$ & Disagree $\%$ of $\mathrm{N}$ & $\mathbf{N}$ & Statistics \\
\hline \multicolumn{5}{|l|}{ Stable relationship } \\
\hline Secure & $59(98.0)$ & $1(2.00)$ & 60 & \\
\hline Avoidant Insecure & $26(93.0)$ & $2(7.00)$ & 28 & $\tau_{c}=0.04$ \\
\hline \multicolumn{5}{|l|}{$\begin{array}{l}\text { You in which one can mirror and } \\
\text { complete oneself }\end{array}$} \\
\hline Secure & $48(80.0)$ & $12(20.0)$ & 60 & \\
\hline Avoidant Insecure & $21(75.0)$ & $7(25.0)$ & 28 & $\tau_{c}=0.04$ \\
\hline \multicolumn{5}{|l|}{$\begin{array}{l}\text { Sharing of innermost feelings, } \\
\text { thoughts, intents and values (like the } \\
\text { family) }\end{array}$} \\
\hline Secure & $40(66.7)$ & $20(33.3)$ & 60 & \\
\hline Avoidant Insecure & $16(57.1)$ & $12(42.9)$ & 28 & $\tau_{c}=0.083$ \\
\hline \multicolumn{5}{|l|}{ Trust } \\
\hline Secure & $42(70.0)$ & $18(30.0)$ & 60 & \\
\hline Avoidant Insecure & $15(54.0)$ & $13(46.0)$ & 28 & $\tau_{c}=0.143$ \\
\hline \multicolumn{5}{|l|}{ Respecting of individual identity } \\
\hline Secure & $43(71.7)$ & $17(28.3)$ & 60 & \\
\hline Avoidant Insecure & $18(64.0)$ & $10(36.0)$ & 28 & $\tau_{c}=0.06$ \\
\hline \multicolumn{5}{|l|}{ Mutual understanding } \\
\hline Secure & $40(66.7)$ & $20(33.3)$ & 60 & \\
\hline Avoidant Insecure & $16(57.1)$ & $12(42.9)$ & 28 & $\tau_{c}=0.083$ \\
\hline \multicolumn{5}{|l|}{ Protection and care } \\
\hline Secure & $23(38.3)$ & $37(61.7)$ & 60 & \\
\hline Avoidant Insecure & $9(32.1)$ & $19(67.9)$ & 28 & $\tau_{c}=0.05$ \\
\hline
\end{tabular}

This explains why violence is "unexpected" for victims of our sample as well as the way in which the dynamics of reaction to abuses are structured.

The studies on intimate partner violence against women (i.e. Ponzio, 2004) report the long and bumpy road that separates the victim from the final decision to leave abusive partner and officially file a complaint against him. Dutton \& Painter (1993), for example, proposed a theory of traumatic bonding, which suggests that the power imbalance and intermittency of abuse typical of abusive relationships enhances the strength of emotional bonds to abusive partners. Even for our sample the rule was not an immediate separation and formal complaint. The complaint came much later. $34 \%$ of the victims' relationships lasted 11 to 20 years; $26 \%$ lasted over 20 years. An ambivalent process seems to be triggered in these cases. For over $80 \%$ of the surveyed, in fact, trusting in the 
partner's continuous promises of change and, above all, the weight of personal, persistent sense of guilt due to the relationship's failure demotivated them from the break-up of the relationship as much as the fear associated with formal complaint itself. Hence, the attempt to save the relationship at all costs, justifying violent acts, almost absolving the abusive partner in the name of a past in which the sharing expectation ideal was the dominant trait. This is a real psychological trap, where disbelief, fear, guilt, nostalgic memory of a lost past, which is still longed for, end up procrastinating the formal complaint and heightening the risk of a more tragic ending.

At this point, with the elements acquired, we move to our conclusion.

\section{Conclusion}

Is love, interaction system involved in the decision-making process regarding sentimental partner selection, predictable in its choices? Linear Determinism, Randomness or Complexity? Each answer presents a different understanding of our lives, on interaction relationships we are involved in, with their way of working and evolution, up to regard, in a possible repercussion chain, issues that seem far from the main question, while instead representing an its further unfolding. In this sense, the way to conceive the risk of victimization in intimate partner violence is the unfolding of a much more general conception of our living world and the natural and social systems that constitute it. Structural Coupling Theory is clearly indicative of a still classic view of interaction systems. The linear determinism underlying it allows the personality structure to be the predictor of partner choice as well as the risk of victimization, with the result of limiting this risk to a one category of women .Nevertheless, our results do not seem to corroborate this linear one-factor determinism underlying Structural Coupling Theory neither its implications. They go rather in the direction of Complexity.

Contemporary scientific epistemology is uncomfortable in conceiving systems as banal machines. Concepts, methods and procedures of classical determinism, with its option of a necessary and linear relationship of input-output causation, have shown to be too mechanistic and insufficient to capture an emerging, surprising, precisely complex, world. Bifurcation, spontaneous self-organization, sensitivity to change of initial conditions, nonlinearity, surprise, emergence, anti-reductionism, irreversibility, nothing seems to have remained the way in which classical science conceived the object of its knowledge and the Newtonian ambition to explain, predict and control events. Systems such as adaptive complex systems or non-banal machines, working by producing emergence, and, consequently, emergent decision-making processes which lose the control on its own products, have become the new system model of the contemporary science. This does not mean a leap into the limbo of randomness, but a harmonization between order and disorder, the recognizing that predictability is limited even if the system is deterministic. Thus, in last decades, Science has re-defined its object and its objectives. All sciences have re-defined their own concepts and pro- 
cedures of analysis, in order to understand complex system in a complex environment, but with the awareness that in the long run the links between cause and effect can be lost in the configuration of a new surprising order, and that what remains is not the predictability but the prefiguration of possible scenarios.

These conceptual categories prove particularly suitable to understand, especially in our modernity, the couple system. And this applies once couple is formed, appearing unstable, ever suspended between order and disorder and open to any outcome and possibility up to enter into chaos, to experiment entropy, its destruction, as well as in the moment of its formation. Adaptive complex system and non-banal machine concepts are more effective to understand the mate selection process than linear deterministic approach, being too mechanistic for a process that shows to include an inextricable dimension of surprise, uncertainty and unpredictability. The volatility of love, the surprising character of his choices, what by complexity language we could call emergence from sensitivity to initial conditions change of many inputs that are today allowed to contribute to choice, is in fact a phenomenal constant of our lives. Nevertheless, this does not mean to admit the randomness, the inexplicability of the process. Complexity is far from linear determinism as well as randomness of interaction. The harmonization of order and disorder seems to be able to better represent what happens when today agents meet and interact to decide whether they may form a couple or not. On the one hand, in modernity, individual biography and identity are freed from established determinations and delivered to the individual, to his free decision. Even love has become a matter of free, independent on tradition constraints, choice, and this has multiplied the variety of factors that can come into play in selection process thus amplifying the possibilities of emergence, the possibilities of sensitivity to even small change of initial conditions and surprising outcomes of the non-linearity of interactions, or, in other terms, the variety of possible scenarios. All possibilities are now open, all choices are possible. On the other hand, partner choice process can be led to an order of explanation, responding, although by autonomy, to impact of personality and psychological, biological, emotional, socio-cultural interacting or co-evolving inputs.

In this regard, models of the nonlinear mechanism underlying system interaction in mate choice decision-making process could shed light on how these factors interact and impact on decision process, with the identification of threshold parameters beyond which a choice is made which would otherwise not be made, bifurcations and unpredictable behaviour are triggered.

Our results seem to confirm our interpretative orientation. To say that all possibilities are open or any choice is possible means to say that any structural coupling is possible, which is exactly what we found in the sample. There are not here just avoidant women, but avoidant women as well as secure and ambivalent women. Even if mate selection process is considered only on the part of the victims and of their personality structure, and considering that the relationship between anxious attachment and intimate violence is a well-established rela- 
tionship, the linear deterministic link between degree of security and partner choice (avoidant (victim)-ambivalent (abuser)) hypothesized from Structural Coupling Theory cannot be supported. Once again, we would repeat that findings cannot exclude that victims' personality structure may affect mate selection process, but security degree is not the predictor of partner's choice and victimization risk. A variety of scenarios emerges. How can this be explained?

Certainly, today, modernity raises the problem of identity. The rule "The more God, the more $P$ ' no longer applies, This is just one of many possibilities of a biography project which is individually and freely chosen, proceeding without solid references points and in an uncertain and unstable way. However, today, for Bauman, the uncertainty of identity is a problem that is less and less felt. The fragility of identity is the image of a modernity which escapes from the project of building a stable identity, from a solidity that increasingly is felt as an unbearable restraint to the freedom to continuously define and redefine one's own self. This freedom requires anything from love, does not look for any anchoring in it. Whereas it is precisely this that, for Beck, still today makes love desirable: being a solution to the problem of identity instability, a romantic antidote to loneliness. In this meaning, in our post-modernity love is still an identity matter.

Faced with these interpretations of intimate life in our post-modernity, our findings would confirm romantic love as one of possible factors which modernity enables to come into play in mate selection, contributing to amplify the sensitivity to changes of initial conditions of interaction system and the possibilities of emergence, surprise, the variety of possible scenarios and choice unpredictability. Sample's victims search stability: they are sensitive to a stable relationship, to a stable You able to complete themselves. This factor seems to break the linearity of the process hypothesized from Structural Coupling Theory. Secure women should not choose anxious partners, able to become abusive partners, and, therefore, we should not have found them in our victims' sample. If the victims (secure woman, but insecure women too) liked the partner, a good reason is also that he showed to share their innermost thoughts, feelings and family values, and to complete them in their search of stability. In this regard, it is interesting to note a substantial alignment with the findings of several other investigations into the state of intimate relationships among American adults, where, despite of retreat from marriage institution, the idea of a You completing one's own self (soul mate hypothesis), the search for an alter with spiritual and emotional affinity, sharing innermost thoughts and feelings, is a strong theme in American sensitivity regarding intimacy (e.g. Whitehead \& Popenoe, 2001; Wilcox, 2010).

Implications arise far from those of Structural Coupling Theory. Victimization risk configures as a possibility which is not limited to a single category of women but indifferently distributed, transversely to personality structure, to all women. Everyone has the possibility to become a victim of intimate partner violence.

In conclusion, we do not wish to legitimize any theoretical presumptions whatsoever, nor indeed could we, given the narrow confines of our research. We 
merely wish to point out that certain our perplexities on Structural Coupling Theory seem to have had some justification, suggesting need for further and more in-depth research.

The issue of abusive personality, although there is ample evidence of a preoccupied or ambivalent personality (Henderson, 2005), nevertheless remains a field worthy to be investigated, taking care to consider, even in this case, the impact of personality psychology criteria, cultural criteria, and their interplay. So, according to Beck, for example, it would be simplistic looking for the causes of couple conflict, with its many sided facets, in personality of individuals, in neurosis, or in early childhood biographical complications, without adequately taking into account love's internal logic, the development of the individualization process which leads to structurally tying into one whole love and hate, preciousness and the impossibility of love itself, amplifying them and discoloring traditional oppositions of meaning of the right and wrong in the self-government which presides over the relationship. For Giddens, as stated above, the current growing increase in gender violence appears to be configured as a structural fact, a symptom of the clash between two different cultural orders, between a modernity that legitimizes female sexual and employment emancipation and a persistent patriarchal culture unable to measure up to this emancipation (see also note 2). Pursuing this line of research will certainly be useful and necessary for the acquisition of enlightening elements in the future. For our part, regarding this purpose, according to our findings, albeit with due caution which any enquiry requires, it seems legitimate to ask whether it is more useful to carry put these appropriate attempts of clarification regardless of the implicit idea of a discriminant factor that refers to structural coupling of partner attachment styles.

\section{References}

Adorno, T. W., \& Horkheimer, M. (1947). Dialektik der Aufklärung. Philosophische Fragmente. [Dialectic of Enlightenment.] Amsterdam: Querido Verlag.

Ainsworth, M. D. (1989). Attachment beyond Infancy. American Psychologist, 44, 709-716. https://doi.org/10.1037/0003-066X.44.4.709

Ainsworth, M. D., \& Bowlby, J. (1991). An Ethological Approach to Personality Development. American Psychologist, 46, 331-341. https://doi.org/10.1037/0003-066X.46.4.333

Ainsworth, M. D., Blehar, M. C., Waters, E., \& Wall, S. (1978). Patterns on Attachment: A Psychological Study of the Strange Situation. Hillsdale, NJ: Erlbaum.

Alberoni, F. (1979). Innamoramento e amore. [Falling in Love.] Milano: Garzanti.

Alì, P. A., \& Naylor, P. B. (2013). Intimate Partner Violence: A Narrative Review of the Biological \& Psychological Explanations for Its Causation. Aggression and Violent Behavior, 18, 373-382. https://doi.org/10.1016/j.avb.2013.07.009

Allen, P. M. (1997). Cities \& Regions as Self-Organizing Systems: Model of Complexity. Journal of Geographical Systems, 4, 103-130.

Allen, P., Mcguire, S., \& McKelvey, B. (2011). The Sage Handbook of Complexity \& Management. London: Sage. 
Ardone, R., \& D'Atena, P. (1988). Il sistema familiare nella fase dell'adolescenza. Un contributo di ricerca. [The Family System in the Adolescent Phase. A Research Contribution.] Terapia Familiare, 28, 19-38.

Arthur, B. W. (1995). Increasing Returns \& Path Dependence in the Economy. Ann Arbor: University of Michigan Press.

Ashby, R. W. (1969). Self Regulation \& Requisite Variety. In F. E. Emery (Ed.), Systems Thinking (pp. 105-124). Middlesex: Penguin Books.

Atlan, H. (1974). On a Formal Definition of Organization. Journal of Theoretical Biology, $45,1-9$.

Axelrod, R. (1984). The Evolution of Cooperation. New York: Basic Books.

Babcock, J. C., Jacobson, N. S., Gottman, J. M., \& Yerington, T. P. (2000). Attachment, Emotion Regulation, and the Function of Marital Violence: Differences between Secure, Preoccupied, and Dismissing Violent and Non-Violent Husbands. Journal of Family Violence, 15, 391-409. https://doi.org/10.1023/A:1007558330501

Bailey, K. E. (1984). Beyond Functionalism: Toward a Nonequilibrium Analysis of Complex Social Systems. British Journal of Sociology, 35, 1-18. https://doi.org/10.2307/590548

Bailey, K. E. (1994). Sociology \& The New Systems Theory. Toward a Theoretical Synthesis. Albany, State: University of New York Press.

Banse, R. (2004). Adult Attachment \& Marital Satisfaction: Evidence for Dyadic Configuration Effects. Journal of Social \& Personal Relationships, 21, 273-282. https://doi.org/10.1177/0265407504041388

Barret, M. (1988). Women's Oppression Today: The Marxist/Feminist Encounter. London: Verso.

Bartholomew, K. (1990). Avoidance of Intimacy: An Attachment Perspective. Journal of Social \& Personal Relationships, 7, 147-178. https://doi.org/10.1177/0265407590072001

Bartholomew, K. (1993). From Childhood to Adult Relationships: Attachment Theory \& Research. In S. Duck (Ed.), Learning about Relationships (pp. 30-62). Newbury Park, CA: Sage Publications.

Bartholomew, K. (1997). Adult Attachment Processes: Individual \& Couple Perspectives. British Journal of Medical Psychology, 70, 249-263. https://doi.org/10.1111/j.2044-8341.1997.tb01903.x

Bartholomew, K., \& Horowitz, L. M. (1991). Attachment Styles among Young Adults: A Test of a Four-Category Model. Journal of Personality \& Social Psychology, 61, 226-244. https://doi.org/10.1037/0022-3514.61.2.226

Bartholomew, K., Henderson, A. J. Z., \& Dutton, D. G. (2001). Insecure Attachment \& Abusive Intimate Relationships. In C. Clulow (Ed.), Adult Attachment and Couple Psychotherapy: Applying the 'Secure Base' Concept in Research and Practise (pp. 43-61). London: Routledge.

Bauman, Z. (1995). Broken Lives, Broken Strategies. In Life in Fragments. Essays in Postmodern Morality. Oxford: Blackwel.

Bauman, Z. (1997). Making \& Unmaking of Strangers. In Postmodernity \& Its Discontentes. Oxford: Blackwell.

Bauman, Z. (2003). Liquid Love: On the Frailty of Human Bond. Cambridge, UK: Polity Press. 
Baumeister, R. F., \& Leary, M. R. (1996). The Need to Belong: Desire for Interpersonal Attachments as a Fundamental Human Motivation. Psychological Bulletin, 117, 497-529. https://doi.org/10.1037/0033-2909.117.3.497

Bech-Sørensen, J., \& Pollet, T. V. (2016). Sex Differences in Mate Preferences: A Replication Study, 20 Years Late. Evolutionary Psychological Sciences, 2, 171-176. https://doi.org/10.1007/s40806-016-0048-6

Beck, U. (1986). Risikogesellschaft. Auf dem Weg in eine \& ere Moderne. [Risk Society: towards a New Modernity.] Frankfurt am Main: Suhrkamp.

Beck, U., \& Beck-Gernsheim, E. (1990). Das ganz normal Chaos der Liebe. Frankfurt am Main: Suhrkamp [(1995). The Normal Chaos of Love.] Cambridge: Polity Press.

Beck, U., \& Beck-Gernsheim, E. (1994). Riskante Freiheiten: Individualisierung in modernen Gesellschaften. [Risky Freedoms: Individualization in Modern Societies.] Frankfuth: Suhrkamp.

Bellah, R. N., \& Madsen, R. (1985). Habits of the Heart. Individualism \& Commitment in American Life. Berkeley: University of California Press.

Benard, C., \& Schlaffer, E. (1981). Liebesgeschichten aus dem Patriarchat. [Love Stories from the Patriarchy.] Rowohlt Tb.: Verlag.

Bowlby, J. (1958). The Nature of the Child's Tie to His Mother. International Journal of Psychoanalysis, 39, 350-373.

Bowlby, J. (1960a). Separation Anxiety. International Journal of Psychoanalysis, 41, 89-113.

Bowlby, J. (1960b). Grief \& Mourning in Infancy \& Early Childhood. In R.S. Eissler, A. Freud, \& M. Kris (Eds.), The Psychoanalytic Study of the Child (Vol. 15, pp. 9-52). New York: International University Press.

Bowlby, J. (1969). Attachment \& Loss (Vol. 1: Attachment). New York: Basic Books.

Bowlby, J. (1973a). Attachment \& Loss (Vol. 2: Separation). New York: Basic Books.

Bowlby, J. (1973b). Self-Reliance \& Some Conditions That Promote It. In R. Gosling (Ed.), Support, Innovation \& Autonomy (pp. 23-48). London: Tavistock Publications.

Bowlby, J. (1979). Self-Reliance \& Some Conditions That Promote It. In J. Bowlby, The Making \& Breaking of Affectional Bond (pp. 103-125). London: Tavistock Publications.

Bowlby, J. (1980). Attachment \& Loss (Vol. 3: Loss, Sadness \& Depression). New York: Basic Books.

Boxer, C. F., Noonan, M. C., \& Whelan, C. B. (2013). Measuring Mate Preferences: A Replication \& Extension. Journal of Family Issues, 36, 163-187.

https://doi.org/10.1177/0192513X13490404

Brennan, K. A., \& Shaver, P.R. (1995). Dimensions of Adult Attachment, Affect Regulation, \& Romantic Relationship Functioning. Personality \& Social Psychology Bulletin 21, 267-283. https://doi.org/10.1177/0146167295213008

Brown, C. (1991). Ballots of Tumult. A Portrait of Volatility in American Voting. Ann Arbor: The University of Michigan Press. https://doi.org/10.3998/mpub.23411

Buss, D. M. (1989). Sex Differences in Human Mate Preferences: Evolutionary Hypothesis Tested in 37 Cultures. Behavioral \& Brain Sciences, 12, 1-49. https://doi.org/10.1017/S0140525X00023992

Buss, D. M., \& Schmitt, D. P. (1993). Sexual Strategies Theory: An Evolutionary Perspective on Human Mating. Psychological Review, 100, 204-232. 
https://doi.org/10.1037/0033-295X.100.2.204

Buss, D. M., Shackelford, T. K., Kirkpatrick, L.A., \& Larsen, J. (2001). A Half Century of Mate Preferences: The Cultural Evolution of Values. Journal of Marriage \& Family, 63, 491-503. https://doi.org/10.1111/j.1741-3737.2001.00491.x

Byng-Hall, J. (1991). The Application of Attachment to Understanding and Treatment in Family Therapy. In C. M. Parker, J. Stevenson-Hinde, \& P. Marris (Eds.). Attachment across the life cycle (pp.199-215). London: Routledge.

Byrne, D. (1998). Complexity Theory \& the Social Sciences: An Introduction. London, UK: Routledge.

Byrne, D., \& Callaghan, G. (2014). Complexity Theory \& the Social Sciences: the state of the art. London, UK: Routledge.

Cate, R. M., Levin, L. A., \& Richmond, L. S. (2002). Premarital Relationship Stability: A Review of Recent Research. Journal of Social \& Personal Relationships, 19, 261-284. https://doi.org/10.1177/0265407502192005

Cilliers, P. (1998). Complexity \& Postmodernism: Understanding Complex Systems. New York: Routledge.

Cluff, R., Hicks, M. W., \& Madsen, C. H. (1994). Beyond the Circumplex Model: I. A Moratorium on Curvilinearity. Family Process, 33, 55-470. https://doi.org/10.1111/j.1545-5300.1994.00455.x

Collins, N. L., \& Read, S. J. (1990). Adult Attachment, Working Models \& Relationship Quality in Dating Couples. Journal of Personality \& Social Psychology, 58, 644-663. https://doi.org/10.1037/0022-3514.58.4.644

Comte, A. (1864). Course de Philosophie Positive. Paris: Bachelier.

Condorelli, R. (2016). Complex Systems Theory. Some Considerations for Sociology. Open Journal of Applied Sciences, 6, 422. https://doi.org/10.4236/ojapps.2016.67044

Condorelli, R. (2017). Surprise of Complexity \& Complexity of Surprise: What Happened to Predictability? Limits and New Possibilities of Complexity for Physical, Psychological and Social Sciences. Journal of Psychology \& Psychotherapy, 7, 302.

https://doi.org/10.4172/2161-0487.1000302

Crittenden, P. (1992). Quality of Attachment in the Preschool Years. Development \& psychopathology, 4, 209-241. https://doi.org/10.1017/S0954579400000110

Davis, S. (1990). Men as Success Objects \& Women as Sex Objects: A Study of Personal Advertisements. Sex Roles, 23, 43-50. https://doi.org/10.1007/BF00289878

Dizard, J. E., \& Gadlin, H. (1990). The Minimal Family. Amherst: University of Massachusetts Press.

Durkheim, É. (1921). La Famille Conjugale. Revue Philosophique, 91, 2-14.

Dutton, D. G., \& Golant, S.K. (2008). The Batterer: A Psychological Profile. New York: the Basic Book.

Dutton, D. G., \& Painter, S. L. (1993). Emotional Attachments in Abusive Relationships: A Test of Traumatic Bonding Theory. Violence \& Victims, 8, 105-120.

Dutton, D. G., Saunders, K., Starzomski, A., \& Bartholomew, K. (1994). Intimacy-Anger and Insecure Attachment as Precursors of Abuse in Intimate Relationships. Journal of Applied Social Psychology, 24, 1367-1386. https://doi.org/10.1111/j.1559-1816.1994.tb01554.x

Eigen, M., \& Schuster, P. (1977). The Hypercycle: A Principle of Natural Self-Organization. Part A: Emergence of the Hypercycle. Naturwissenschaften, 64, 
541-565. https://doi.org/10.1007/BF00450633

Elias, N. (1939). Über den Prozeß der Zivilisation. [On the Civilizing Process.] Basel: Verlag Haus zum Falken.

Engels, F. (1884). Der Ursprung der Familie, des Privateigenthums und des Staats. [The Origin of the Family, Private Property, and the State.] Hôttingen-Zürich: Verlag der Schweizerischer Volksbuchh \& lung.

Feeney, J. A, \& Noller, P. (1996). Adult Attachment. Thous \& Oaks, CA: Sage. https://doi.org/10.4135/9781452243276

Fletcher, G. J. O., \& Simpson, J. A. (2000). Ideal Standards in Close Relationships: Their Structure and Functions. Current Directions in Psychological Science, 9, 102-105. https://doi.org/10.1111/1467-8721.00070

Foucault, M. (1976). Histoire de la sexualité. La volonté de savoir. [History of Sexuality.] Paris: Gallimard.

Frazier, P. A, Byer, A. L., Fischer, A. R., Wright, D. M., \& Debord, K. A. (1996). Adult Attachment Style and Partner Choice: Correlational \& Experimental Findings. Personal Relationships, 3, 117-136. https://doi.org/10.1111/j.1475-6811.1996.tb00107.x

Galimberti, C., \& Farina, M. (1990). FACES III: uno strumento per la ricerca e l'osservazione clinica della famiglia. [FACES III: A Tool for Clinical Research and Clinical Observation.] Milano: Vita e Pensiero.

Gelles, R. J. (1999). Through a Sociological Lens: Social Structure \& Family Violence. In C. M. Albers (Ed.), Sociology of Families (pp. 299-308). Thousand Oaks, CA: Sage.

Gell-Mann, M. (1994). The Quark \& the Jaguar. Adventures in the Simple \& the Complex. New York: Freeman W.H. \& Company.

Gerberding, J. L., Binder, S., Hammond, R. W, \& Arias, I. (2003). Costs of Intimate Partner Violence against Women in the United States. Atlanta, Georgia: Department of Health and Human Services Centers for Disease Control and Prevention.

Giddens, A. (1992). The Transformation of Intimacy. Sexuality, Love \& Eroticism in Modern Societies. Cambridge: Polity Press.

Gill, R. T. (1997). Progress, Ideology, \& the Decline of the American Family. Lanham, MD: Rowman \& Littlefield.

Gillath, O., Karantzas, G. C., \& Fraley, R. C. (2016). Adult Attachment: A Concise Introduction to Theory and Research. New York: Elsevier.

Goodwin, B. (1994). How the Leopard Changed Its Spots, Evolution of Complexity. London: Phoenix.

Green, R. G., Harris, R. H., Forte, J. A., \& Robinson, M. (1991). Evaluating FACES III and the Circumplex Model in 2,440 Families. Family Processes, 30, 55-73.

https://doi.org/10.1111/j.1545-5300.1991.00055.x

Haken, H. (2004). Synergetics. Introduction and Advanced Topics. Berlin: Springer. https://doi.org/10.1007/978-3-662-10184-1

Haken, H., \& Graham, R. (1971). Synergetik. Die Lehre vom Zusammenwirken. [Synergetics.] Umschau in Wissenschaft und Technik, 6, 191-195.

Harlow, H. F., \& Zimmermann, R. R. (1959). Affectional Responses in the Infant Monkey. Science, 130, 421-432. https://doi.org/10.1126/science.130.3373.421

Hartmann, H. I. (1976). Capitalism, Patriarchy, \& Job Segregation by Sex. Signs. Journal of Women in Culture \& Society, 1, 137-169. https://doi.org/10.1086/493283

Harvey, D. L., \& Reed, M. (1997). Social Sciences as the Study of Complex Systems. In D. L. Kiel, \& E. W. Elliott (Eds.), Chaos Theory in the Social Science: Foundations and 
Applications (pp. 295-323). Ann Arbor: The University of Michigan Press.

Hazan, C., \& Shaver, P. R. (1987). Romantic Love Conceptualized as an Attachment Process. Journal of Personality and Social Psychology, 52, 511-524. https://doi.org/10.1037/0022-3514.52.3.511

Hazan, C., \& Shaver, P. R. (1994). Deeper into Attachment Theory. Psychological Inquiry, 5, 68-79. https://doi.org/10.1207/s15327965pli0501_15

Hazan, C., \& Zeifman. D. (1999). Pair Bonds as Attachments: Evaluating the Evidence. In J. Cassidy, \& P. R. Shaver (Eds.), Handbook of Attachment: Theory, Research \& Clinical Applications (pp. 336-354). New York: The Guilford Press.

Heise, L. L. (2012). Determinants of Partner Violence in Low \& Middle-Income Countries: Exploring Variation in Individual \& Population Level Risk. London, UK: London School of Hygiene Tropical Medicine.

Henderson, A. J. Z., Bartholomew, K., Trinke, S. J., \& Kwong, M. J. (2005). When Loving Means Hurting: An Exploration of Attachment \& Intimate Abuse in a Community Sample. Journal of Family Violence, 20, 219-230. https://doi.org/10.1007/s10896-005-5985-y

Hochschild, A. R. (2003). The Commercialization of Intimate Life: Notes from Home \& Work. Berkeley: University of California Press.

Holland, J. H. (1998). Emergence: From Chaos to Order. Reading, Massachusetts: Addison-Wesley.

Holmes, J. (1993). Bowlby and Attachment Theory. London: Routledge.

Holmes, B. M., \& Johnson, K. R. (2009). Adult Attachment and Romantic Partner Preference: A Review. Journal of Social and Personal Relationships, 26, 833-852. https://doi.org/10.1177/0265407509345653

Holtzworth-Munroe, A., Stuart, G. L., \& Hutchinson, G. (1997). Violent versus Nonviolent Husbands: Differences in Attachment Patterns, Dependency, and Jealousy. Journal of Family Violence, 11, 314-331. https://doi.org/10.1037/0893-3200.11.3.314

Kasser, T., \& Sharma, Y. S. (1999). Reproductive Freedom, Educational Equality, and Females' Preference for Resource-Acquisition Characteristics in Mates. Psychological Science, 10, 374-377. https://doi.org/10.1111/1467-9280.00171

Kauffman, S. (1995). At Home in the Universe: The Search for Laws of Self-Organization and Complexity. Oxford: Oxford University Press.

Kesner, J. E., Julian, T., \& McKenry, P. C. (1997). Application of Attachment Theory to Male Violence toward Female Intimates. Journal of Family Violence, 12, 211-228. https://doi.org/10.1023/A:1022840812546

Kirkpatrick, L. A., \&. Davis, K. E. (1994). Attachment Style, Gender and Relationship Stability: A Longitudinal Analysis. Journal of Personality and Social Psychology, 66, 502-512.

https://doi.org/10.1037/0022-3514.66.3.502

Langton, C. G. (1990). Computation at the Edge of Chaos. Physica D, 42, 12-37. https://doi.org/10.1016/0167-2789(90)90064-V

Larsen, M. M. (2016). Theoretical \& Empirical Perspectives on Intimate Partner Violence. In M. Larsen (Ed.), Health Inequities Related to Intimate Partner Violence against Women, Social Disparities in Health and Health Care (pp. 13-29). Switzerland: Springer International Publishing. https://doi.org/10.1007/978-3-319-29565-7_2

Lasch, C. (1977). Heaven in a Heartless World. New York: Basic Books. 
Lorenz, K. (1949). Er redete mit dem Vieh, den Vögeln und den Fischen. [King's Salomon Ring: New light on Animal Ways (1952).] Wien: Verlag Borotha Schoeler.

Loriedo, C., \& Picardi, A. (2000). Dalla teoria generale dei sistemi alla teoria dell'attaccamento. Percorsi e modelli della psicoterapia sistemico-relazionale. [From the General Theory of Systems to the Theory of Attachment. Practices and Models of Systemic-Relational Psychotherapy.] Milano: Franco Angeli.

Loriedo, C., Di Giusto, M., \& De Bernardis, G. (2011). Attrazione e scelta. Incontrarsi e formare una coppia. [Attraction and Choice. Meet and Form a Couple.] Milano: Salani Editore.

Luhmann, N. (1986). The Autopoiesis of Social Systems. In F. Geyger, \& J. van der Zowen. (Eds.), Sociocybernetics Paradoxe (pp. 172-192). London: Sage.

Luhmann, N. (1990). Essays on Self Reference. New York: Columbia University Press.

Luhmann, N., \& De Giorgi, R. (1992). Teoria della società [Theory of Society] Milano: Franco Angeli.

Main, M., \& Goldwin, R. (1995). Adult Attachment Scoring \& Classification System. Berkeley: Department of Psychology, University of California.

Main, M., George, C., \& Kaplan, N. (1985). Adult Attachment Interview. Berkeley: Department of Psychology, University of California.

Marcuse, H. (1964). One-Dimensional Man: Studies in the Ideology of Advanced Industrial Society. Boston: Beacon Press.

Maturana, H., \& Varela, F. G. (1984). El arbol del conocimiento. [The Tree of Knowledge.] Santiago: Editorial Universitari.

Mazzoni, S., \& Tafà, M. (2007). Intersoggettività nella famiglia: Procedure multi metodo per l'osservazione e la valutazione delle relazioni familiari. [Inter-Subjectivity in the Family: Multiple Methods for Observing and Evaluating Family Relationships.] Milano: Franco Angeli.

McBarnett, M. (1996). Complexity in the Evolution of Public Opinion. In L. D. Kiel, \& E. W. Elliott (Eds.), Chaos Theory in the Social Science: Foundations and Applications (pp. 165-196). Ann Arbor: University of Michigan Press.

McDaniel, R. R. \& Driebe, I. (2010). Uncertainty \& Surprise in Complex Systems. New York: Springer.

Miller, G. F. (1998). How Mate Choice Shaped Human Nature: A Review of Sexual Selection \& Human Evolution. In C. Crawford, \& D. L. Krebs (Eds.), Handbook of Evolutionary Psychology: Ideas, Issues, and Applications (pp. 87-129). Mahwah: Lawrence Erlbaum Associates.

Miller, J. H., \& Page, S.E. (2007). Complex Adaptive Systems. An Introduction to Computational Models of Social Life. Princeton: Princeton University Press.

Mitleton-Kelly, E. (2003). Complex Systems and Evolutionary Perspectives on Organisations: The Application of Complexity Theory to Organisations. Amsterdam: Pergamon.

Morin, E. (1977). La Méthode. I. La nature de la nature [Method. Vol. I. toward a Study of Humankind] Paris: Le Seuil.

Morin, E. (2008). On Complexity. Advances in Systems Theory, Complexity, and the Human Sciences. Cresskill, NJ: Hampton Press.

Mullen, P. E., Pathè, M., \& Purcell, R. (2009). Stalkers and Their Victims. Cambridge: Cambridge University Press.

Nesteruk, O., \& Gramescu, A. (2012). Dating \& Mate Selection among Young Adults from Immigrant Families. Marriage and Family Review, 48, 40-58. 
https://doi.org/10.1080/01494929.2011.620732

Nicolis, J. S. (1991). Chaos and Information Processing. Singapore: World Scientific. https://doi.org/10.1142/0984

Olson, D. H. (1986). Circumplex Model VII: Validation Studies \& FACES III. Family Process, 25, 337-351. https://doi.org/10.1111/j.1545-5300.1986.00337.x

Olson, D. H., Gorall, D. M., \& Tiesel, J. W. (2004). FACES IV Package. Minneapolis: Life Innovation, Inc.

Olson, D. H., Portner, J., \& Lavee, Y. (1985). “Faces III”: Family Adaptability \& Cohesion Evaluation Scales, Family Social Science. St. Paul: University of Minnesota.

Parsons, T. (1951). The Social System. New York: The Free Press.

Piaget, J. (1936). Origins of Intelligence in the Child. London: Routledge.

Pietromonaco, P. R., \& Carnelley, K. B. (1994). Gender and Working Models of Attachment: Consequences for Perception of Self \& Romantic Relationship. Personal Relationships, 1, 3-26. https://doi.org/10.1111/j.1475-6811.1994.tb00055.x

Ponzio, G. (2004). Crimini segreti: Maltrattamento e violenza alle donne nella relazione di coppia. [Secret Crimes: Maltreatment and Violence against Women in Relationships Couple.] Milano: Baldini Castoldi Dalai.

Popenoe, D. (1992). The Declining American Family. New York: Rutgers University.

Prigogine, I. (1997). The End of Certainty. New York: The Free Press.

Prigogine, I. (2010). Surprises in a Half Century. In R. R. McDaniel, \& D. J. Driebe (Eds.), Uncertainty \& Surprise in Complex Systems (pp. 13-16). New York: Springer.

Prigogine, I., \& Nicolis, G. (1977). Self-Organization in Non-Equilibrium Systems: From Dissipative Structures to Order through Fluctuations. New York: Wiley.

Prigogine, I., \& Stengers, I. (1979). La Nouvelle Alliance. Metamorphose de la Science. Paris: Gallimard.

Read, S. J., \& Miller, L. C. (1989). Interpersonalism: Towards a Goal Based Theory of Persons in Relationships. In L. Pervin (Ed.), Goal Concepts in Personality \& Social Psychology (pp. 413-472). Hillsdale, NJ: Erlbaum.

Reed, M., \& Harvey, D. L. (1992). The New Science \& The Old: Complexity \& Realism in the Social Sciences. Journal for the Theory of Social Behaviour, 22, 353-380. https://doi.org/10.1111/j.1468-5914.1992.tb00224.x

Rodriguez-Menes, J., \& Safranoff, A. (2012). Violence against Women in Intimate Relations: A Contrast of Five Theories. European Journal of Criminology, 9, 584-602. https://doi.org/10.1177/1477370812453410

Sawyer, K.R. (2005). Social Emergence. Societies as Complex Systems. Cambridge: Cambridge University Press. https://doi.org/10.1017/CBO9780511734892

Schiepek, G. K., Fartacek, C., Sturm, J., Kralovec, K., Fartacek, R., \& Pöderl, M. (2011). Nonlinear Dynamics: Theoretical Perspectives and Application to Suicidology. Suicide Life Threatening Behavior, 41, 661-675. https://doi.org/10.1111/j.1943-278X.2011.00062.x

Shackelford, T. K., Schmitt, D. P., \& Buss, D. M. (2005). Universal Dimensions of Human Mate Preferences. Personality and Individual Differences, 39, 447-458. https://doi.org/10.1016/j.paid.2005.01.023

Shalev, O., Baum, N., \& Itzhaky, H. (2015). “Whose Marriage is this?”-Mate Selection Patterns in Modern Orthodox Society in Israel: A Dialogue between Two Cultural Systems. Journal of Psychology and Psychotherapy, 5, 3. 
https://doi.org/10.4172/2161-0487.1000181

Shannon, C. E., \& Weaver (1948). A Mathematical Theory of Communication. The Bell System Technical Journal, 27, 379-423. https://doi.org/10.1002/j.1538-7305.1948.tb01338.x

Shaver, P., \& Hazan, C. (1992). Adult Romantic Attachment Process: Theory and Evidence. In D. Perlman, \& W. Jones (Eds.), Advances in Personal Relationships Outcomes (Vol. IV, pp. 29-70). London: Jessica Kingsley Publisher.

Shaver, P., Hazan, C., \& Bradshaw, D. (1988). Love as Attachment: The Integration of Tree Behavioral System. In R. J. Sternberg, \& M. L. Barnes (Eds.), The Psychology of Love (pp. 39-68). New Haven: Yale University Press.

Simmel, G. (1906). Psychologie der Diskretion. [Discretion.] Der Tag, 2, 4 settembre.

Simmel, G. (1921). Fragment über die Liebe. Logos; Internationale Zeitschrift für Philosophie der Kultur. [A Fragment on Love.] Bd. X. Tübingen: Mohr. (Posthumous Publication)

Simpson, J. A., \& Rholes, S. W. (2015). Attachment Theory \& Research: New Directions and Emerging Themes. New York: Guilford Publications.

Simpson, J. A. (1990). Influence of Attachment Styles on Romantic Relationships. Journal of Personality and Social Psychology, 59, 971-980.

https://doi.org/10.1037/0022-3514.59.5.971

Spencer, H. (1896). The Principles of Sociology. London: Williams \& Norgat.

Sroufe, A. L., \& Waters, E. (1977). Attachment as an Organizational Construct. Child Development, 48, 1184-1199. https://doi.org/10.2307/1128475

Stamovlasis, D., \& Vaiopoulou, J. (2017). The Role of Dysfunctional Myths in a Decision-Making Process under Bounded Rationality: A Complex Dynamical Systems Perspective. Nonlinear Dynamics, Psychology \& Life Sciences, 21, 267-288.

Stevenson-Hinde, J., \& Shouldice, A. (1995). Maternal Interactions \& Self-Reports Related to Attachment Classifications at 4.5 Years. Child Development, 66, 583-596. https://doi.org/10.2307/1131936

Strauss, C., Morry, M. M., \& Kito, M. (2012). Attachment Styles \& Relationship Quality: Actual, Perceived, and Ideal Partner Matching. Personal Relationship, 19, 14-36. https://doi.org/10.1111/j.1475-6811.2010.01333.x

Surra, C. A., \& Huston, T. L. (1987). Mate Selection as a Social Transition. In D. Perlman, \& S. Duck (Eds.), Intimate Relationships: Development, Dynamics, and Deterioration (pp. 53-88). Beverly Hills: Sage.

Tönnies, F. (1887). Gemeinschaft und Gesellschaft. [Comunity and Society.] Leipzig: Reislad.

Truss, C., \& Gill, J. (2004). Human Resource Management: A Complexity Perspective. Paper to the Organisations, Innovation \& Complexity: New Perspectives on the Knowledge Economy Conference, 9-10 September 2004, Manchester University, Manchester. https://doi.org/10.1111/j.1748-8583.2004.tb00133.x

Uskul, A. K, Lalonde, R. N., \& Cheng, L. (2007). Views on Interracial Dating among Chinese \& European Canadians: The Roles of Culture, Gender, and Mainstream Cultural Identity. Journal of Social and Personal Relationships, 24, 891-911. https://doi.org/10.1177/0265407507084189

Visani, E., Di Nuovo, S., \& Loriedo, C. (2014). Il FACES IV: Il modello circonflesso di Olson nella clinica e nella ricerca. [FACES III. Olson's Circumplex Model in Clinic and Research.] Milano: FrancoAngeli. 
Von Bertalanffy, L. (1968). General System Theory. Foundations, Development, Applications. New York: George Braziller.

Von Foerster, H. (1960). On Self-Organizing Systems \& Their Environments. In M. C. Yovitz, \& S. Cameron (Eds.), Self-Organizing Systems (pp. 31-50). Oxford: Pergamon Press.

Weber, M. (1922). Wirtschaft und Gesellschaft. [Economy and Society.] Tübingen: Mohr.

Weiss, R, S. (1982). Attachment in Adult Life. In C. M. Parkes, \& J. Stevenson-Hinde (Eds.), The Place of Attachment in Human Behavior (pp. 171-184). New York: Wiley.

Whitehead, B. D. (1997). The Divorce Culture. New York: Knopf.

Whitehead, B. D., \& Popenoe, D. (2001). Who Wants to Marry a Soul Mate? In B. D. Whitehead, \& D. Popenoe (Eds.), The State of Our Unions (pp. 6-16). New Brunswick, NJ: Rutgers University's National Marriage Project.

Wilcox, B. W. (2010.) When Marriage Disappears: The Retreat from Marriage in Middle America. In B. W. Wilcox, E. Marquardt, D. Popenoe, \& B. D. Whitehead (Eds.), The State of Our Unions. Marriage in America (pp. 13-61). Charlottesville, VA: National Marriage Project University of Virginia.

Zentner, M., \& Mitura, K. (2012). Stepping out of the Caveman's Shadow Nations' Gender Gap Predicts Degree of Sex Differentiation in Mate Preferences. Psychological Science, 23, 1176-1185. https://doi.org/10.1177/0956797612441004

Zhang, S., \& Kline, S. L. (2009). Can I Make My Own Decision? A Cross-Cultural Study of Perceived Social Network Influence in Mate Selection. Journal of Cross-Cultural Psychology, 40, 3-23. https://doi.org/10.1177/0022022108326192 